\title{
Minimizing the Ecological Risk of Combined-Sewer Overflows in an Urban River System by a System-Based Approach
}

\author{
Jeng-Chung Chen ${ }^{1}$; Ni-Bin Chang, M.ASCE${ }^{2}$; Chiee-Young Chen ${ }^{3}$; and Chiu-Shia Fen ${ }^{4}$
}

\begin{abstract}
As urban and suburban areas expand, the problem of sewage disposal spreads as well. Inappropriate planning of a sewage management system could impair water quality, destroy habitat, and threaten public health. Simply building a sewage interceptor system along the urban river corridor to handle the wastewater effluents without regard to the impacts from combined-sewer overflows (CSOs) in the storm events cannot fulfill the ultimate goal of environmental restoration in the receiving water body. This study therefore carries out a system-based assessment to search for the optimal operating strategy of the interceptor facilities with respect to biocomplexity or biodiversity in an urban river system. In particular, it focuses on the richness of the fish community in the biological systems, the effect of stress on the fish community by storm events, and their capacity for adaptive behavior in response to the CSOs' impact in the Love River estuarine system, South Taiwan. By integrating the biological indicators in an environmental context, two simulation models describing the quality and quantity of storm water and their impact on the river water quality are calibrated and verified. The interactions of natural systems and engineered systems covering both spatial and temporal aspects can then be explored in terms of the predicted levels of dissoved oxygen (DO) along the river reaches so as to strengthen an ultimate optimal search for the best operational alternative for the interceptor system. In view of the inherent complexity of integrating simulation outputs at various scales to aid in building the optimization step, three regression submodels were derived beforehand. These submodels present a high potential for exhibiting, eliciting, and summarizing the nonlinear behavior between the CSO impacts and the DO levels in the river reaches. With the aid of such findings, this study finally applies a linear programming model to determine the optimal size of a constructed storage pond (i.e., a detention pond), based on several types of storm events in the study area. This is proved essential for minimizing the ecological risk in such a way so as to indirectly improve the biodiversity in the estuarine river system.
\end{abstract}

\section{DOI: XXXX}

CE Database subject headings: Water quality; Combined sewer overflow; Restoration; Simulation; Optimization; Environmental issues; River systems; Urban areas.

\section{Introduction}

Many urban river systems have been suffering for centuries from wastewater discharges during the urbanization (Latimer and Quinn 1996; Perguson et al. 2001). In recent years, the focus of sustainability in many urban development plans has been evolving, from the engineering efforts for pollution control to the in-

\footnotetext{
${ }^{1}$ Associate Professor, Dept. of Environmental Engineering and Sanitation, Fooyin Univ., Kaohsiung, Taiwan, ROC.

${ }^{2}$ Professor, Dept. of Environmental Engineering, Texas A\&M Univ. Kingsville, Kingsville, TX 78363.

${ }^{3}$ Associate Professor, Dept. of Marine Environmental Engineering, National Kaohsiung Institute of Marine Technology, Kaohsiung, Taiwan, ROC.

${ }^{4}$ Assistant Professor, Dept. of Environmental Engineering and Science, Feng-Chia Univ., Taichung, Taiwan, ROC.

Note. Associate Editor: Robert G. Arnold. Discussion open until March 1, 2005. Separate discussions must be submitted for individual papers. To extend the closing date by one month, a written request must be filed with the ASCE Managing Editor. The manuscript for this paper was submitted for review and possible publication on March 5, 2002; approved on June 9, 2003. This paper is part of the Journal of Environmental Engineering, Vol. 130, No. 10, October 1, 2004. (CASCE, ISSN 0733-9372/2004/10-1-XXXX/\$18.00.
}

vestigation of system dynamics of coupled natural and human systems, so as to aid in finding a better strategy for ecosystem restoration (Fruge 1995; Lorenz and Koski 1995; Seaman 1995). It was indeed the case facing the Love River estuarine system, Kaohsiung, South Taiwan, when the issue of biodiversity in the urban river system was considered in recent years. Back to the early 1980s, when the engineering efforts for building a sewer collection and interceptor system along the river corridor and constructing a large-scale coastal wastewater treatment plant for effluent disposal were fully justified by "value engineering" perspectives, almost no one was concerned about the issues of biocomplexity or biodiversity in the Love River estuarine system. In the 1990s, engineering efforts have led to a gradual improvement of river water quality in the downstream area. This was evidenced and confirmed by the fact that the concentration of biochemical oxygen demand $\left(\mathrm{BOD}_{5}\right)$ went below $15 \mathrm{mg} / \mathrm{L}$ and the dissolved oxygen (DO) rose to $3-5 \mathrm{mg} / \mathrm{L}$ on an annual average basis (EPA, Taiwan, 1993-1999). As this improvement occurred, it was then that the problem of lower biodiversity of fish species in the Love River estuarine system could begin to receive attention with respect to the impact of combined-sewer overflows (CSOs). While the official investigation with regard to estuarine and river ecology indicates that more than 85 fish species could 


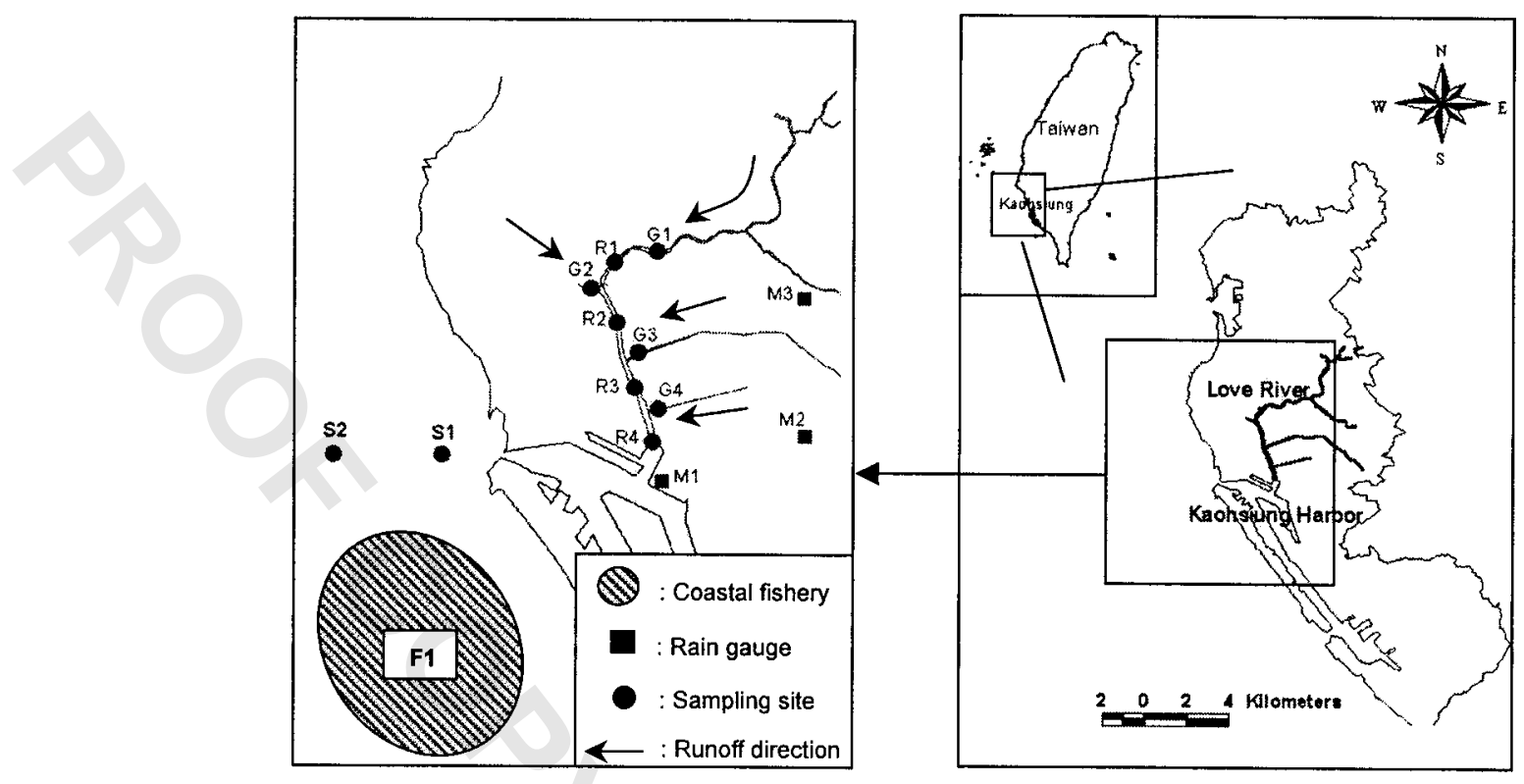

Fig. 1. Geographical location of study area and sampling sites

be found in the neighboring river systems in South Taiwan, only 17 fish species appeared in the Love River estuarine system within the time period of 1993-1995 and 1997 to 1998 (Chen and Hsiao 1996; Huang 1996; Chen et al. 1999). Simply building an interceptor system along the river corridor to intercept and transport daily wastewater flows to remote treatment plants without regard to the CSOs' impacts in the storm events cannot fulfill the ultimate goal of environmental restoration for this urban river system (Attrill 1998).

Many developed countries have proposed various real time control schemes to improve the efficiency of sewer system operation (Nyberg et al. 1996; Vazquez et al. 1997; Weinreich et al. 1997; Petruck et al. 1998; Entem et al. 1998; Cassar and Verworn 1999). Previous development of stormwater management programs covers broad areas, and many studies have been performed regarding automatic assessment of urban stormwater (Leiser 1974), general guidelines for urban stormwater management and technology (Lager 1977), specific control measures (US EPA 1995), control and treatment technologies (Moffa 1989), enchancing urban watershed mangement skills (US EPA 1993), and stormwater storage (Walesh and Carr 2000). But almost none of these directly links the stormwater or CSOs' management issues with biocomplexity or biodiversity in the river system. To preserve, improve, and restore the ecosytem integrity in the estuarine rehabilitation process, this study therefore carries out a systembased assessment to promote a comprehensive investigation of CSOs' impacts with regard to the biocomplexity or biodiversity in the urban river system. In particular, it focuses on the richness of the fish community in the biological systems, the effect of stress on the fish community by storm events, and their capacity for adaptive behavior in response to the CSO's impacts in the Love River estuarine system, South Taiwan. A sampling campaign with respect to both biological and environmental aspects was carried out in the late 1990s and the early part of 2000 to aid in characterizing the "critical limit" of DO in the fish community. By integraing the biological indicators in an environment context, two simulation models describing the quality and quantity of storm water and its impacts to the river water quality are calibrated and verified in this study. One is the Storm Water Management Model
(SWMM), which is a well-known software package developed by the US EPA in 1969-1971; the other is the Love River Hydrodynamic and Water Quality (LRHWQ), which is a customized software package developed by the writers to fit these specific research needs (Fen 2001). The output from cases where both the simulation processes are gained can be fed into the optimization analysis as input for investigating an optimal control scheme associated with each main gate in the interceptor system. The interactions of natural systems and engineered systems can then be explored in terms of the predicted levels of DO in the river system so as to improve the strength of ecosystem rehabilitation. In view of the inherent complexity of integrating simulation outputs to aid in finding the optimal control scheme, some regression submodels must be derived beforehand with high potential for exhibiting, eliciting, and summarizing the nonlinear behavior between the CSO impacts and the levels of DO in the river system. Final systems engineering analysis for building a storage pond with an optimal size may become achievable based on such a high degree of interdisciplinary integration.

\section{Methodology}

\section{Study Site}

Kaohsiung City, located in the southwestern part of Taiwan, is a rapidly growing international harbor (i.e., ranked fifth in the world in 2001) and business center with an area of $154 \mathrm{sq} \mathrm{km}$ and a total population of approximately 1.5 million in 2001. The Love River, with its origin in Kaohsiung County, runs through the northwestern part of Kaohsiung City (i.e., the downtown area) and enters the harbor about $2.5 \mathrm{~km}$ east of the harbor entrance. It is approximately $15 \mathrm{~km}$ long and drains an area of about 6,800 ha with two major branches as Pao-Chu channel and No. 2 channel from the east. The upper watershed includes agricultural, residential, and industrial land uses with a river width of $45-85 \mathrm{~m}$. Its lower stretch of $1.6 \mathrm{~km}$ passes through the center of the city, where it drains predominately residential and commercial districts. This stretch, with stone-grouted banks is straight and 100 

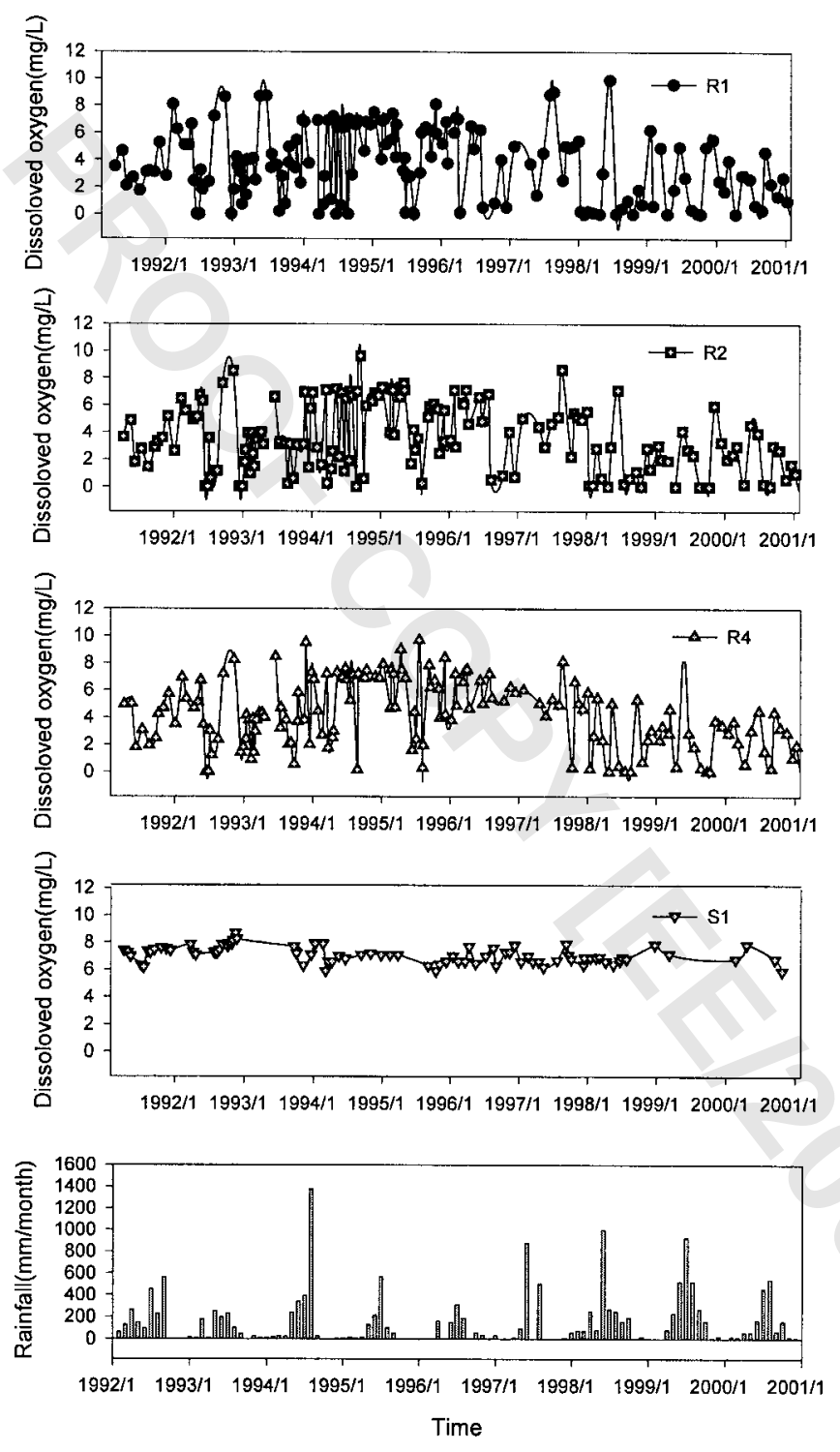

Fig. 2. Long-term monitoring of rainfall intensities and dissolved oxygen concentrations at R1, R2, R4, and S1

$120 \mathrm{~m}$ wide. A narrow park, built as part of the sewer construction plan runs along the banks of that section with facilities for recreational purposes and aesthetic enjoyment. It provides one of the most beneficial sites for sightseeing in this city. Both the Kaohsiung harbor and the Love River have been badly polluted due to continuously receiving untreated sewage since 1965. Different levels of government agencies have initiated different scales of long-term or short-term water quality monitoring programs of river and harbor water since then. The measures of $\mathrm{pH}, \mathrm{DO}$, $\mathrm{BOD}_{5}$, suspended solids (SS), and temperature are generally regarded as the main parameters being observed in this river system. In addition to official investigations, research-oriented programs have also initiated a couple of site-specific sampling efforts in this region. Fig. 1 describes the geographical location of the study area and the sampling sites selected by both government agencies and researchers.

The sewers constructed since 1980 mainly include trunk sewers, main sewers, and submain sewers in the central part of the city. The estimated average flow and maximum flow that can be shipped to a remote coastal wastewater treatment plant are
Table 1. Sampling Efforts Covered in This Study

\begin{tabular}{cccc}
\hline $\begin{array}{c}\text { Sampling } \\
\text { site }\end{array}$ & $\begin{array}{c}\text { River water } \\
\text { sampling }\end{array}$ & $\begin{array}{c}\text { Storm runoff } \\
\text { sampling }\end{array}$ & $\begin{array}{c}\text { Biological } \\
\text { sampling }\end{array}$ \\
\hline G1 & & $\mathrm{X}$ & \\
G2 & & $\mathrm{X}$ & \\
G3 & & $\mathrm{X}$ & \\
G4 & $\mathrm{X}$ & $\mathrm{X}$ & $\mathrm{X}$ \\
R1 & $\mathrm{X}$ & $\mathrm{X}$ & $\mathrm{X}$ \\
R2 & $\mathrm{X}$ & $\mathrm{X}$ & \\
R3 & $\mathrm{X}$ & $\mathrm{X}$ & $\mathrm{X}$ \\
R4 & $\mathrm{X}$ & & \\
S1 & $\mathrm{X}$ & & $\mathrm{X}$ \\
S2 & & & Loading \\
F1 & & Base flow & of BOD \\
& & in dry day & in dry day \\
& Catchments area & (CMS) & (kg/day) \\
(ha) & 2.01 & 37,639 \\
Interceptor & 3,689 & 0.12 & 2,346 \\
\hline G1 & 506 & 0.61 & 11,195 \\
G2 & 782 & 0.15 & 2,662 \\
G3 & 169 & & \\
G4 & & & \\
\hline
\end{tabular}

400,000 and 560,000 $\mathrm{m}^{3} /$ day, respectively. During storm events, the flow rate in the trunk sewer becomes a limiting factor. Obviously, the excess flow resulting from the storm event must be disposed of in the Love River, which could result in a sudden devastating impact to the local ecosystem. Rainfall-runoff patterns were extensively investigated during the time period between 1993 and 1997. Fig. 2 displays a set of records of rainfall intensities and DO concentrations measured at four gate locations (R1, R2, R4, and S1). It appears that the DO levels in the Love River fluctuate over time in response to the variations of rainfallrunoff patterns. Concerning the environmental rehabilitation of the Love River ecosystem, the search for an optimal management strategy for gate operation is essential. To properly handle those residual CSOs, using the systems engineering approach to building a storage pond with optimal size and preparing an emergency response program in the coastal wastewater treatment plant to control the impact of CSOs in the summer seasons is needed.

\section{Study Design}

This study began with a search of the "critical limit" of DO in the fish community that could be applied as a biological indicator and reflects the required control effort in the engineered interceptor system. It was followed by more detailed discussion's covering the proper integration of two simulation models and one optimization model for use in systems analysis. After successful application of calibration and verification for each specific simulation model, the integrated optimization analysis would enable the creation of invaluable insights for determining the required optimal control scheme for the interceptor system and the optimal size of a storage pond (i.e., detention pond) to be engineered. A field survey of fish richness and rainfall/runoff patterns from both qualitative and quantitative aspects was required for linking the interactions between natural and human systems. Table 1 summarizes the entire effort in field surveys that are essential to fulfilling all the goals of this study. The detailed discussions related to both ecological and environment aspects will be addressed below. 


\section{Critical Limit Study of Fish Community}

This estuary and coastal sea are the high productivity zones where many aquatic species find nursery grounds for their young. The water quality deterioration due to intensive urbanization and industrialization along the Koahsiung coastal region has stressed the organisms living in this region. The field surveys covering the entire coastal and estuarine region were carried out in a thorough biological monitoring program to assist in assessing the impact of CSOs and ocean outfalls (Chen et al. 2002). In this program, we used a demersal trawl ( $5 \mathrm{~m}$ in width, $2.5 \mathrm{~cm}$ mesh size at cod end) to investigate the fish community in the Kaohsiung coastal region (marked by F1 in Fig. 1). Each sampling campaign was conducted on a monthly basis and used a boat that was usually kept at 2 to 3 knots speed for 30 min intervals. In addition, a threelayer gill net $(8 \times 20 \times 8 \mathrm{~cm}$ mesh size for the inside, middle, and outer layer) was utilized to collect fish samples around the estuarine area. Every sampling campaign was conducted for $30 \mathrm{~min}$ at three sites (marked by R1, R3, and R4 in Fig. 1). The initial findings confirmed that of the more than 85 fish species that could be found in the neighboring river and coastal water systems in South Taiwan, only 17 fish species appeared in the Love River estuarine system (Chen et al. 2002). The major fish species found in the Love River include Nematalosa com, Leiognathus equulus, Megalops Cyprinodes, Chanos chanos, Leiognathus nuchalis, Gerres filamentosus, and Liza macrolepis (Chen et al. 2002).

In order to explore the "critical limit" of DO in the estuarine region, ecological response analysis was designed to examine three primary elements: the relationship between stressor levels and ecological effects, the plausibility effects that may occur or are occurring as a result of exposure to stressor, and linkages between ecological effects and assessment endpoints when the latter cannot be directly measured. In particular, laboratory analysis in this study concentrated on the living thresholds of young Liza macrolepis and Chanos chanos under a full exposure at a lower level of DO (Chen et al. 2002). The lethal concentrations can be reported in terms of three levels, including $16 \%$ (i.e., lethal concentration required to kill $16 \%$ of the tested animals), $50 \%$, and $84 \%$ (i.e., $\mathrm{LC}_{16}, \mathrm{LC}_{50}$, and $\mathrm{LC}_{84}$ ). Because these tests seldom exceed $96 \mathrm{~h}$, their main value lies in evaluating short-term effects of DO concentration. Given that $\mathrm{LC}_{50}$ is commonly characterized as the median effect level in the ecological risk assessment, the corresponding DO level is thus selected as the "critical limit" in this study. In summary, the observed DO level associated with $\mathrm{LC}_{50}$ is in between 0.8 and $1.1 \mathrm{mg} / \mathrm{L}$, while the saturated oxygen concentration is close to $9.0 \mathrm{mg} / \mathrm{L}$ under normal conditions. As a result, the DO level of $0.5 \mathrm{mg} / \mathrm{L}$ was finally chosen as a typical lethal concentration and is named the "critical limit" in the local fish community when receiving the stormwater impacts. This study also concurred with previous observation that a DO level below $3 \mathrm{mg} / \mathrm{L}$ may be regarded as a condition which could impose an obvious negative ecological impact in this river system in the long run (Jones 1964; Vaughan and Russell 1982; Alan 1995). Therefore, the DO level $3 \mathrm{mg} / \mathrm{L}$ was finally chosen as the harmful condition in this study. In practical application, it is desirable to determine an effective management strategy for operating the interceptor system so that the anticipated DO level can be maintained in all river reaches over a given control period.

\section{Field Surveys of Combined-Sewer Overflows and Stream Water Quality}

In order to properly identify the pollution load during rainfall, the stormwater runoff was periodically sampled at four locations, as marked by G1, G2, G3, and G4 in Fig. 1, nearby the existing interceptor system during several significant storm events. The sampling area covers $92.4 \%$ of the Love River watershed. New rain gauges were installed at three locations, as marked by M1, M2, and M3 in Fig. 1, to record rainfall intensity during these storm events. The collected information from these storm events is summarized in Table 2. Simultaneous recording of rainfall intensity, flow rate of run-off in the drainage channel, and the DO concentration in the run-off and the river water to identify the water quality was successfully performed within two storm events which occurred on July 21 and 25, 2001. The follow-on laboratory analyses based on the standard methods of the EPA in Taiwan provide essential information with regard to the runoff concentrations of $\mathrm{BOD}_{5}$, SS, total phosphorus (Total-P), and ammonianitrogen $\left(\mathrm{NH}_{3}-\mathrm{N}\right)$. The gross effects of pollution impact to the Love River were described in terms of several pollutographs.

$S W M M$ analysis would serve as part of the simulation studies to aid in the prediction of the DO level in the river. Then the subsequent simulation of river water quality during these storm events, using the $L R H W Q$ model as a tool, would enable us to confirm the compliance situations of DO levels based on the "critical limit" of DO applied in the fish community. Performing a credible $S W M M$ application requires performing a two-stage analysis. The first stage analysis focuses on a calibration study utilizing the data measured on July 25,2001 , and the second stage analysis is to apply a verification study based on the rainfall record measured on July 11, 2001. To properly determine the impacts of stormwater to river water quality, the calibration and

Table 2. Sampling Campaign during the Rainfall Events between 2000 and 2001

\begin{tabular}{|c|c|c|c|c|c|}
\hline $\begin{array}{l}\text { Survey } \\
\text { date }\end{array}$ & $\begin{array}{l}\text { Time period of } \\
\text { rainfall event }\end{array}$ & Sampling time period & $\begin{array}{l}\text { Duration } \\
\text { (min) }\end{array}$ & $\begin{array}{c}\text { Total } \\
\text { accumulated } \\
\text { rainfall } \\
(\mathrm{mm})\end{array}$ & $\begin{array}{l}\text { Average } \\
\text { rainfall } \\
\text { intensity } \\
(\mathrm{mm} / \mathrm{h})\end{array}$ \\
\hline $2000 / 6 / 11$ & $13: 43-13: 54$ & $1343-1558$ & 11 & 10 & 54.5 \\
\hline $2000 / 6 / 13$ & $17: 00-23: 40$ & $2000 / 6 / 13-6 / 17$ & 400 & 43.5 & 6.5 \\
\hline $2000 / 7 / 4$ & $15: 27-15: 38$ & $1520-1715$ & 11 & 9.5 & 51.8 \\
\hline $2000 / 7 / 8$ & $13: 05-18: 52$ & $1205-1915$ & 347 & 5.5 & 0.9 \\
\hline $2000 / 7 / 27$ & $17: 09-19: 40$ & $1715-1940$ & 151 & 93 & 36.9 \\
\hline $2000 / 8 / 22$ & $9: 52-17: 04$ & $940-1715$ & 432 & 8.5 & 1.2 \\
\hline 2000/9/1 & $11: 52-13: 27$ & $1245-1600$ & 95 & 26 & 16.4 \\
\hline 2001/7/11 & $15: 30-4: 00$ (next day) & $1500-1900$ & 780 & 539 & 41.5 \\
\hline $2001 / 7 / 25$ & $14: 20-15: 40$ & $1600-830$ (next day) & 80 & 90 & 67.5 \\
\hline $2001 / 8 / 2$ & $16: 45-17: 45$ & $1600-1900$ & 60 & 11.5 & 11.5 \\
\hline
\end{tabular}




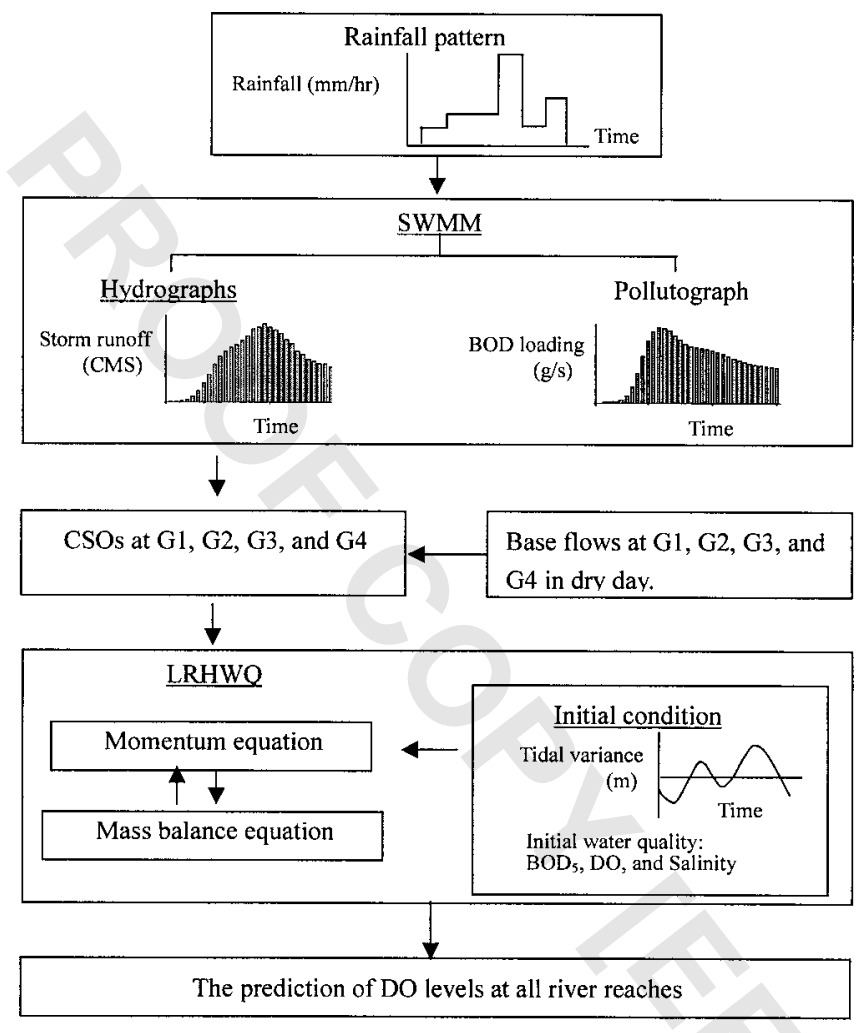

Fig. 3. Conceptual flowchart of how to integrate the Storm Water management and Love River Hydrodynamic and Water Quality models

verification of the $L R H W Q$ model is essential. It relies on two sampling campaigns conducted on July 25, 2001 and June 13-17, 2000 , respectively. The river authority opened all the gates nearby the interceptor system to release residual CSOs during these storm events so that parameters of concern (i.e., $\mathrm{BOD}_{5}$ and DO) were meaningful in the ecological risk assessment. Sampling sites mainly included the main gate at G1 and the other three gates at G2-G4 being installed for controlling tributary inflows.

Table 3. Database Used for $2^{7-4}$ Fractional Experimental Design Conditional to the Time Used for Interception is Less Than $30 \mathrm{~min}$

\begin{tabular}{ccccccc}
\hline & & \multicolumn{3}{c}{ Intercepting time of gate } & \\
\cline { 3 - 5 } & $\begin{array}{c}\text { Initial } \\
\text { BOD }_{5} \text { level } \\
(\mathrm{mg} / \mathrm{L})\end{array}$ & & & & & $\begin{array}{c}\text { Rainfall } \\
\text { intensity } \\
(\mathrm{min})\end{array}$ \\
Case & $Q w$ & $T_{1}$ & $T_{2}$ & $T_{3}$ & $T_{4}$ & $R$ \\
\hline 1 & 10 & 30 & 10 & 30 & 10 & 100 \\
2 & 10 & 10 & 30 & 10 & 30 & 100 \\
3 & 50 & 30 & 10 & 10 & 30 & 44 \\
4 & 50 & 10 & 10 & 30 & 30 & 44 \\
5 & 10 & 30 & 30 & 30 & 30 & 18 \\
6 & 50 & 30 & 30 & 10 & 10 & 18 \\
7 & 50 & 10 & 30 & 30 & 10 & 0 \\
8 & 10 & 10 & 10 & 10 & 10 & 0 \\
\hline
\end{tabular}

\section{Simulation Analyses}

In order to determine the gross pollution impact from the rainfall to the receiving water body during the storm events, the two simulation models must be used one after the other. The output from the $S W M M$ analysis can be fed into the $L R H W Q$ model as input for investigating the spatial and temporal variations of DO levels in the river reaches during the storm events.

$S W M M$ is a widely used model for simulation of runoff quantity and quality in storm events. It consists of several modules, in which the RUNOFF block is used to predict the run-off impact and the TRANSPORT block is used to calculate flows routed through the sewer system (Huber and Dickinson 1988; Roesner 1988). A 25-year frequency, 1-h duration design storm was selected in order to determine what control was necessary in terms of storage of future regulator overflows. The data used for these projections consisted of 10 years of hourly rainfall data for the years 1990-1999. These data were used as input to the SWMM $R U N O F F$ block and the SWMM TRANSPORT block to project overflows that cannot be captured by the present sewer system. On the other hand, the $L R H W Q$ model, which exhibits a detailed capability of addressing the hydrokinetic characteristics of tidal force, is a two-dimensional (2D) laterally integrated numerical simulation model. The simulation analysis using the $L R H W Q$ model was performed over 42 river reaches, in which each length of reach was fixed at $100 \mathrm{~m}$. The reach width, however, may vary spatially and the values used in this study are the same as measured along the river system. To achieve a $2 \mathrm{D}$ simulation framework, each reach was further partitioned into six layers vertically. The hydrodynamic characteristics, including the flow velocities and surface elevation at each reach during the storm events, can be calculated by a momentum equation as follows:

$$
\begin{aligned}
\frac{\partial \bar{u}}{\partial t} & +\bar{u} \frac{\partial \bar{u}}{\partial x}+\bar{v} \frac{\partial \bar{u}}{\partial z}+g\left[\frac{\partial \zeta}{\partial x}+\alpha(z+\zeta) \frac{\partial \bar{C}_{S}}{\partial x}\right] \\
& =\frac{1}{w} \frac{\partial}{\partial z}\left(w \varepsilon_{z} \frac{\partial \bar{u}}{\partial z}\right)-\frac{1}{w} \frac{f}{8} \bar{u}|\bar{u}|\left(\frac{d b_{1}}{d z}+\frac{d b_{2}}{d z}\right)
\end{aligned}
$$

where $\bar{u}, \bar{v}$ mean the average velocities of river flow in $x$ - and $z$ directions, respectively, at each reach $\left(\mathrm{m} \mathrm{s}^{-1}\right) ; b_{1}, b_{2}=$ length of vertical layer at a side of reach $(\mathrm{m}) ; \zeta=$ change of elevation due to the tidal effect at each reach $(\mathrm{m}) ; w=$ width of river at each reach (m); $z=$ depth of river at each reach (m); $\alpha=$ coefficient for correcting the value of water density $\left(\rho=\rho_{0}[1+\alpha \bar{S}], \rho=\right.$ density of

Table 4. Database Used for $2^{7-4}$ Fractional Factorial Experimental Design Conditional to the Time Used for Interception is More Than 30 min

\begin{tabular}{ccccccc}
\hline & & \multicolumn{3}{c}{ Intercepting time of gate } & \\
\cline { 3 - 5 } & $\begin{array}{c}\text { Initial } \\
\text { BOD }_{5} \text { level } \\
(\mathrm{mg} / \mathrm{L})\end{array}$ & & & & & $\begin{array}{c}\text { Rainfall } \\
\text { intensity } \\
(\mathrm{min})\end{array}$ \\
Case & $Q w$ & $T_{1}$ & $T_{2}$ & $T_{3}$ & $T_{4}$ & $R$ \\
\hline 1 & 10 & 60 & 30 & 60 & 30 & 100 \\
2 & 10 & 30 & 60 & 30 & 60 & 100 \\
3 & 50 & 60 & 30 & 30 & 60 & 44 \\
4 & 50 & 30 & 30 & 60 & 60 & 44 \\
5 & 10 & 60 & 60 & 60 & 60 & 18 \\
6 & 50 & 60 & 60 & 30 & 30 & 18 \\
7 & 50 & 30 & 60 & 60 & 30 & 0 \\
8 & 10 & 30 & 30 & 30 & 30 & 0 \\
\hline
\end{tabular}




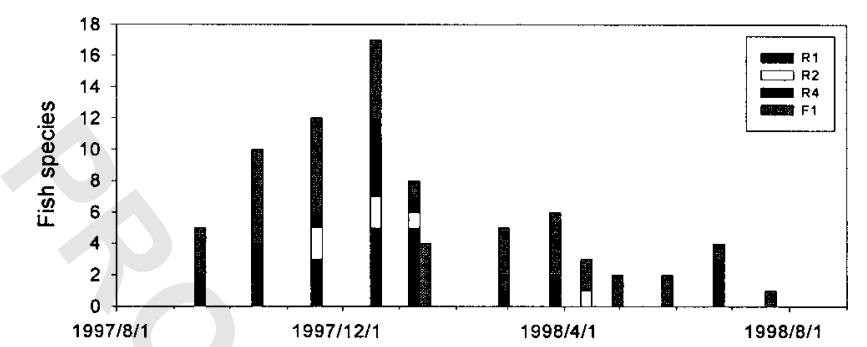

(a)

The biodiversity patterns

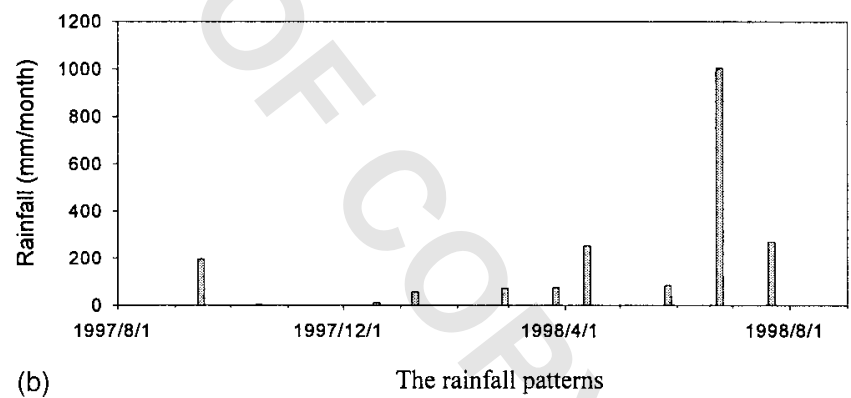

Fig. 4. Biodiversity and rainfall patterns during 1997 to 1998

water with salinity $\bar{S}$ and $\rho_{0}=$ density of pure water); $\varepsilon_{z}=$ eddy viscosity in $z$ direction $\left(\mathrm{m}^{2} \mathrm{~s}^{-1}\right) ; f=$ coefficient of friction (unitless); $g=$ acceleration due to gravity $\left(\mathrm{m} \mathrm{s}^{-2}\right)$; and $\bar{C}_{S}=$ average concentration of constituent or salinity $\left(\mathrm{g} \mathrm{m}^{-3}\right)$.

The principal pollution impacts of stormwater to all river reaches mainly come from four gates, as marked by G1-G4 in Fig. 1. They consist of one installed for controlling the upstream flow, as marked by G1 in Fig. 1, and the other three installed for controlling the lateral discharges, as marked by G2-G4. The water quality parameters to be estimated by this model may include: (1) conservative substances, like salinity, for which concentrations change over hydrodynamic conditions, and (2) nonconservative substances, like $\mathrm{BOD}_{5}$ and $\mathrm{DO}$, that they may be consumed due to chemical or biochemical degradation and increased from resuspension or reaeration in addition to the inherent transport effects of advection and dispersion. The governing equation for the mass balance for any specific water quality constituent considered may be expressed as follows:

$$
\begin{aligned}
& \frac{\partial\left(w \bar{C}_{s}\right)}{\partial t}+\frac{\partial\left(w \bar{u} \bar{C}_{s}\right)}{\partial x}+\frac{\partial\left(w \bar{v} \bar{C}_{s}\right)}{\partial z} \\
& =\frac{\partial}{\partial x}\left(w K_{x} \frac{\partial \bar{C}_{s}}{\partial x}\right)+\frac{\partial}{\partial z}\left(w K_{z} \frac{\partial \bar{C}_{s}}{\partial z}\right)+w P+\frac{Q L P}{\Delta x \Delta z}
\end{aligned}
$$

where $P=$ sink or source $\left(\mathrm{g} \mathrm{m}^{-3} \mathrm{~s}^{-1}\right) ; Q L P=$ waste load from lateral discharge of sewage in the storm flooding time period $\left(\mathrm{g} \mathrm{s}^{-1}\right)$; and $K_{x}, K_{z}=$ dispersion and turbulent diffusion coefficients in the axes $x$ and $z$, respectively $\left(\mathrm{m}^{2} \mathrm{~s}^{-1}\right)$.

Fig. 3 depicts the conceptual flowchart of how these two simulation models can be integrated into one holistic scenario for environmental impact assessment. Upon receiving the rainfall information every minute through a wireless or leased line transmission system, the SWMM model (having been calibrated and verified before) would be able to make an immediate prediction of the quantity and quality of runoff and continuously send the predicted waste load information of CSOs (i.e., pollutographs) to $L R H W Q$ every 5 min within a $10-\mathrm{h}$ time period. $L R H W Q$ would take these inputs and the real-time tidal information into

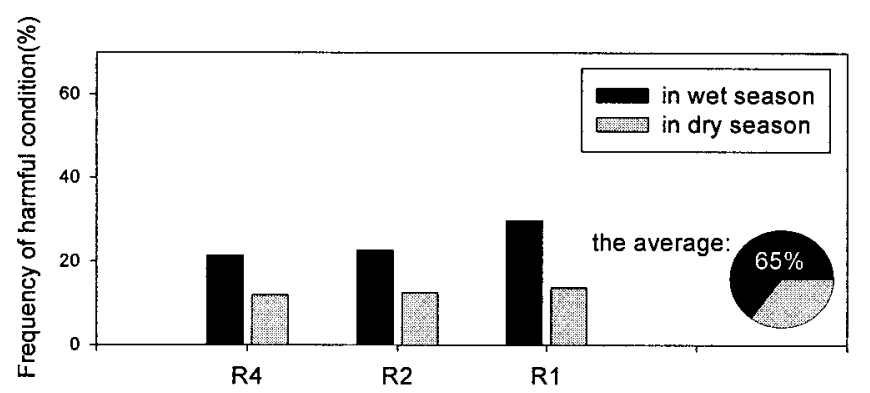

(a)

The impact of harmful events

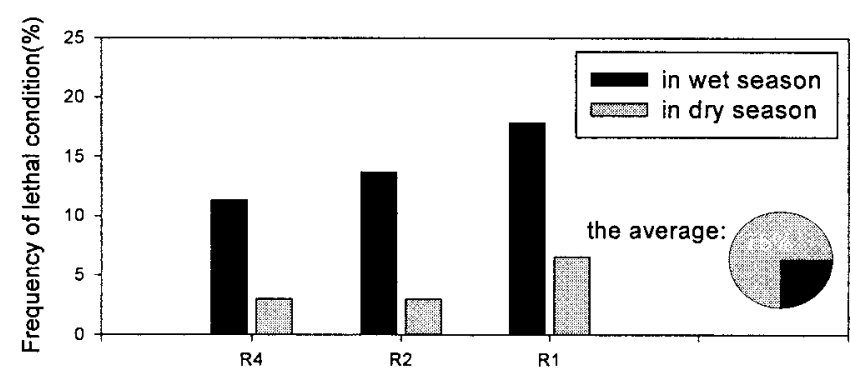

(b)

The impact of lethal events

Fig. 5. Frequency distributions associated with harmful and lethal conditions in fish community during 1991-2000

account at the same time for the predictions of spatial and temporal variations of DO levels for all river reaches. Such analysis may be performed through a web site so that all the decision makers working for different agencies may see the same results at the same time and perform shared-vision modeling analysis (Chen et al. 2002).

\section{Optimization Analysis}

The aim of this optimization analysis is to search for an optimal control scheme for the operation of each gate, given that the compliance with a water quality standard in terms of "critical limit" of DO level in the fish community is the managerial goal applied in the storm events. To achieve this goal, the objective function is defined to reflect the principle of cost-effectiveness to design an optimal size storage pond for detention for the sewer system. Two essential constraints cover the considerations of the ecological risk assessment. They consist of the average DO concentration that has to be maintained in general in the entire region $\left(\mathrm{DO}_{\mathrm{ave}}\right)$ and the minimum DO concentration that has to be achieved in specific in all sensitive river reaches $\left(\mathrm{DO}_{i}\right)$ within a $12-\mathrm{h}$ simulation time period. They are implicitly linked with the harmful and lethal conditions, respectively. The lower limits of these two constraints are 0.5 and $3 \mathrm{mg} / \mathrm{L}$, respectively. The living organism, however, is even more sensitive to ammonia than DO level in the water body (Heath 1995). Once in a while, the adaptation capability of fry to the changing environment could be underestimated; and therefore it could be assumed that the fry will not face immediate lethal impact unless the river reaches experience anaerobic conditions that could allow nitrite nitrogen in the CSOs to be converted to ammonia in the reducing environment.

In view of the complexity in linking the simulation output from both $S W M M$ and $L R H W Q$ simulations for the optimization step, the use of three linear regression submodels to collectively describe the nonlinear behavior between the CSOs' impact and the changing levels of dissolved oxygen in the river system is 


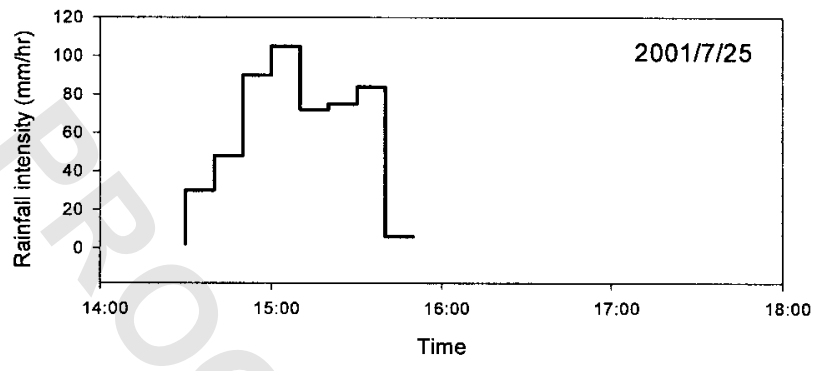

(a) The rainfall pattern applied for SWMM calibration

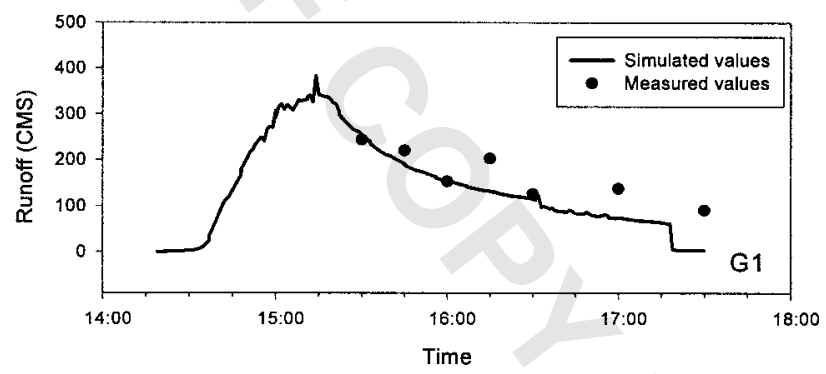

(b) The calibration of run-off flow rate at G1

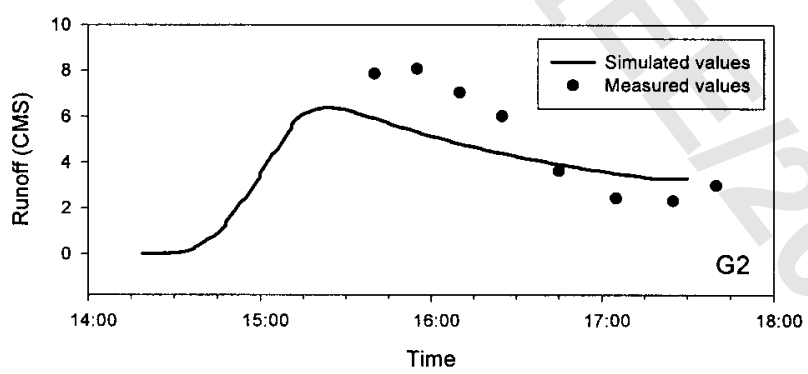

(c)

The calibration of run-off flow rate at $\mathrm{G} 2$

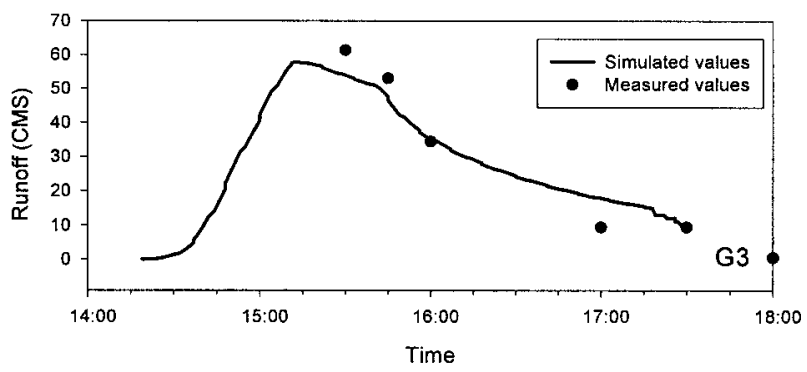

(d)

The calibration of run-off flow rate at G3

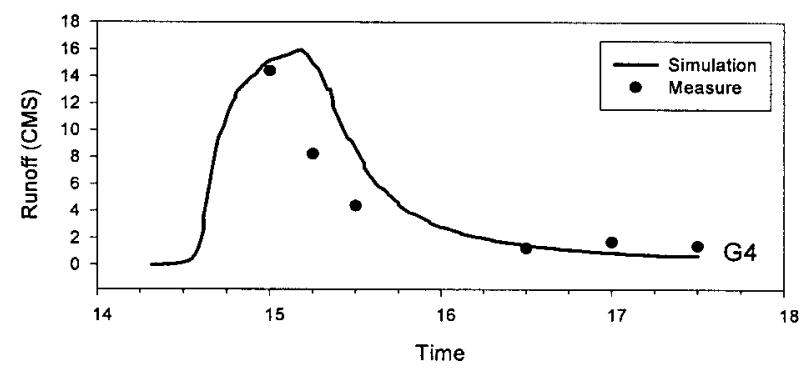

(e) The calibration of run-off flow rate at G4

Fig. 6. Calibration of the Storm Water management with respect to run-off prediction

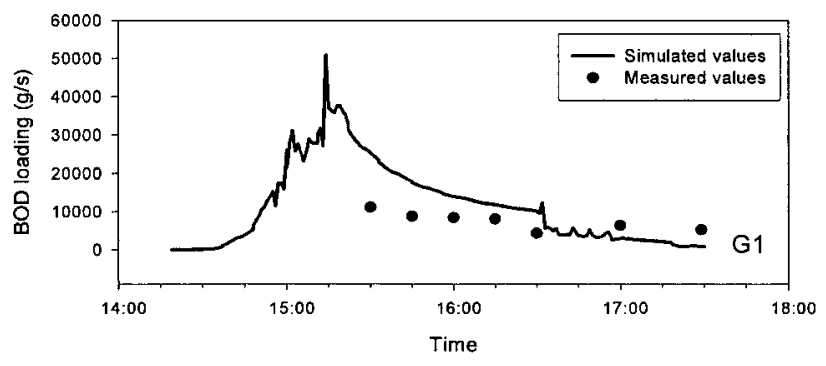

(a) The calibration of BOD loading at G1

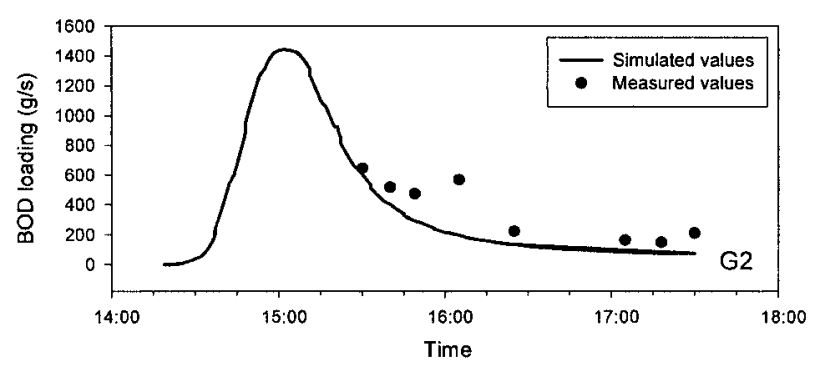

(b) The calibration of BOD loading at G2

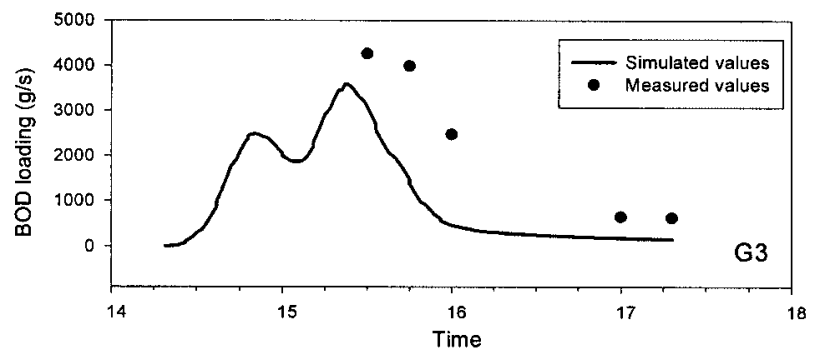

(c)

The calibration of BOD loading at G3

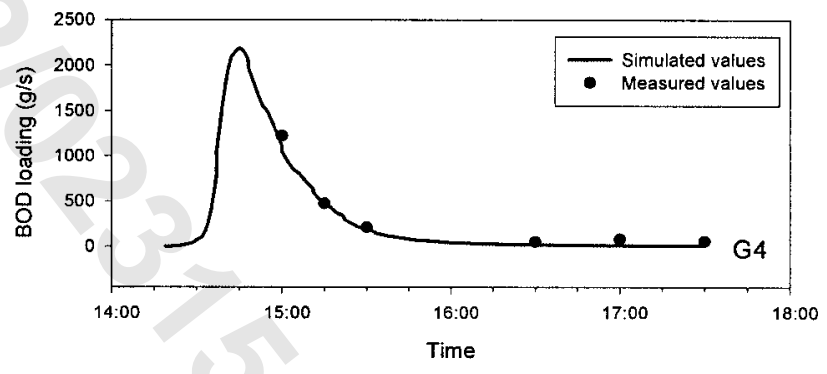

(d)

The calibration of BOD loading at G4

Fig. 7. Calibration of the Storm Water management with respect $\mathrm{BOD}_{5}$ prediction

needed (Bikangaga and Nassehi 1995; Ng et al. 1996; Curtis and Tarang 1997; Falconer and Lin 1997; Whitehead et al. 1997; Reda and Beck 1999). They are to be employed as an integral part of the objective function and constrains in the optimization model. Six exogenous parameters, consisting of rainfall intensity, initial level of $\mathrm{BOD}_{5}$ in the river, and time period spent for interception at four main gates, were included in the regression analysis. To successfully extract the essential, applicable, and effective information from the enormous amounts of simulation scenarios and to fit them in the optimization framework properly, experimental design in a statistical sense has to be applied. The major methods of experimental design generally include factorial design, D-optimal design, and uniform design. In this study, we selected the method of factorial design in which all parameters except the 


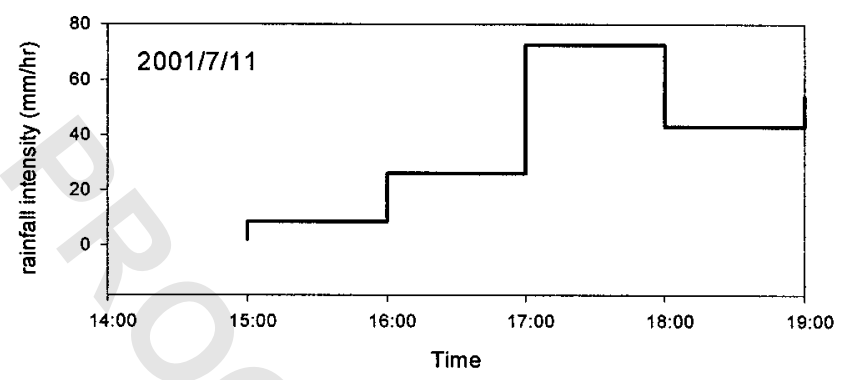

(a) The rainfall pattern applied for SWMM verification

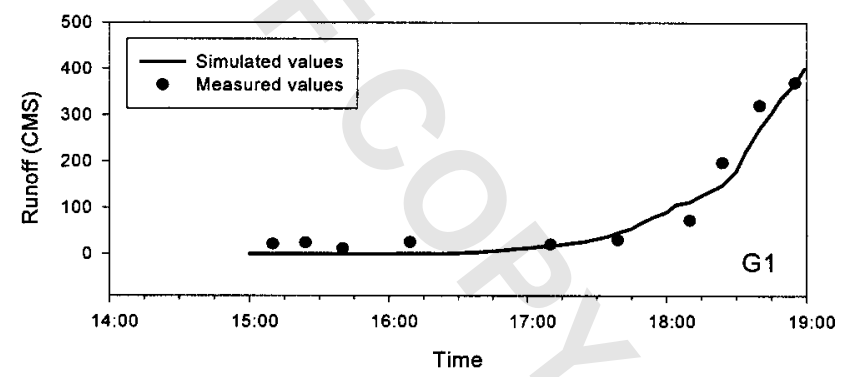

(b)

The verification of run-off flow rate at $\mathrm{Gl}$

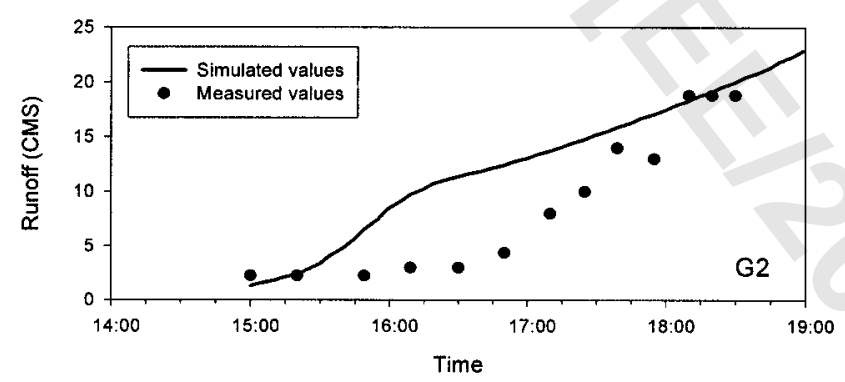

(c)

The verification of run-off flow rate at $\mathrm{G} 2$

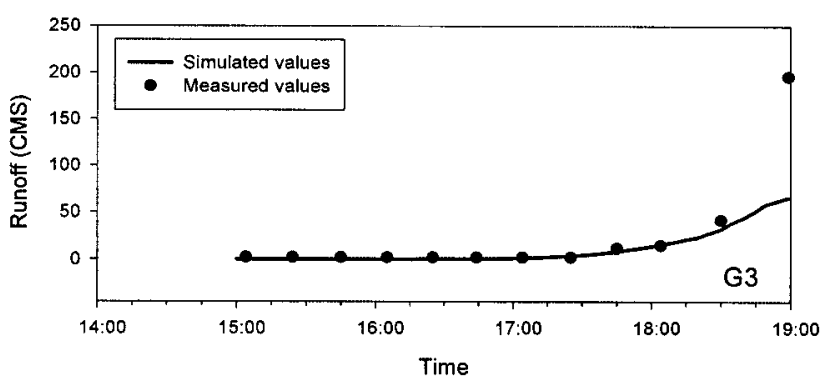

(d)

The verification of run-off flow rate at $\mathrm{G} 3$

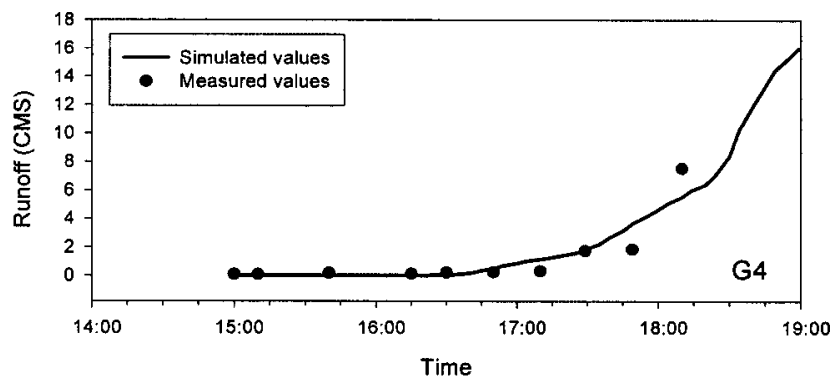

(e)

The verification of run-off flow rate at $\mathrm{G} 4$

Fig. 8. Verification of the Storm Water management with respect to run-off prediction

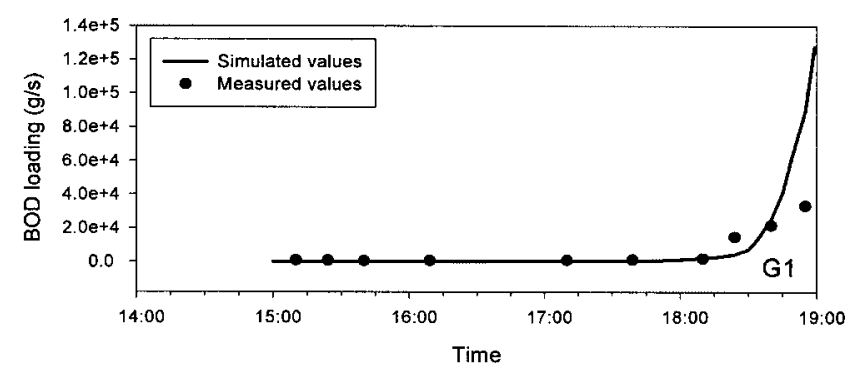

(a)

The verification of BOD loading at G1

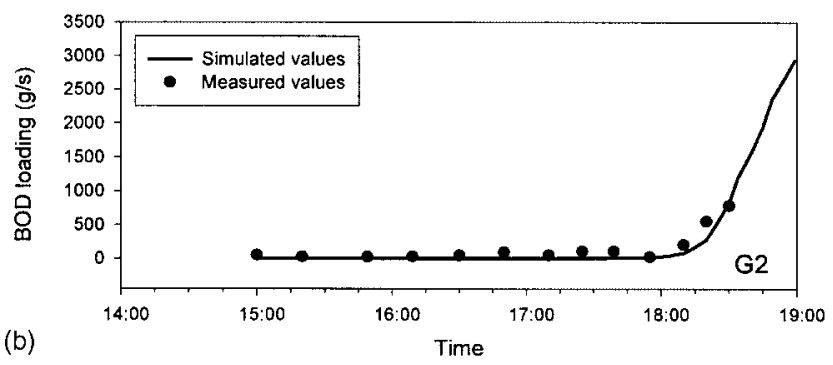

The verification of BOD loading at $\mathrm{G} 2$

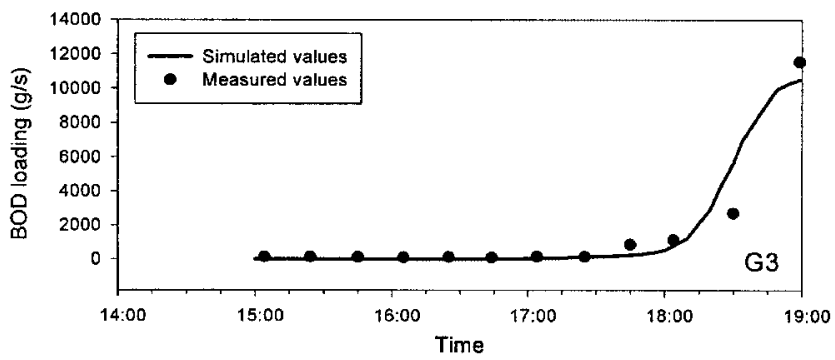

(c)

The verification of BOD loading at $\mathrm{G} 3$

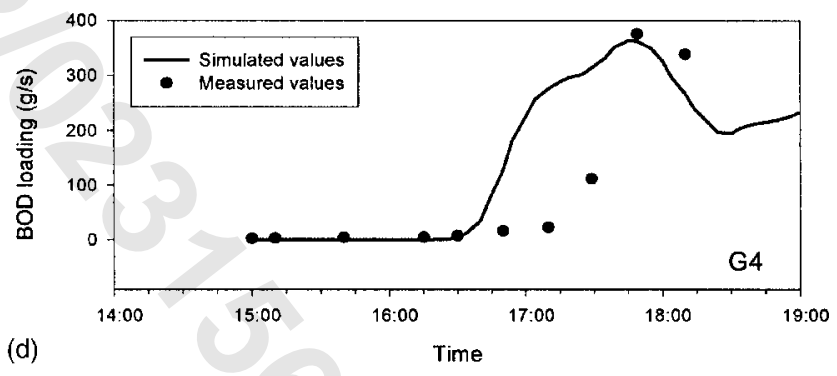

The verification of BOD loading at G4

Fig. 9. Verification of the Storm Water management with respect to $\mathrm{BOD}_{5}$ prediction

rainfall pattern were considered as two levels. Thus the rainfall pattern was addressed by a set of doubled two-level factors. Therefore this experimental design merits a credit via the use of a $2^{7-4}$ fractional factorial design (Wu and Hamada 2000). Tables 3 and 4 summarize the database used in this experimental design. As a consequence, this design reduces the computational loading from 128 times to 8 times in the test runs. As a result of this reduction, the multiplicative effect in terms of those considered parameters that might result in higher order terms could be ignored. The credibility of linear regression models derived should be finally confirmed by the associated $R^{2}$ and $F$ values in the regression output. 


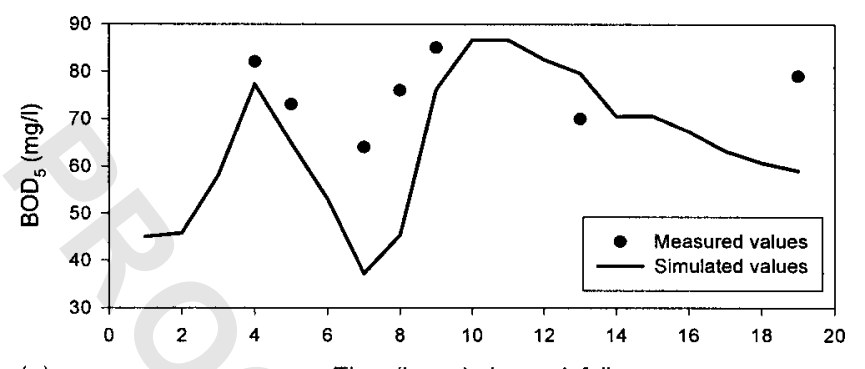

(a)

Time (hours) since rainfall

Model calibration in terms of $\mathrm{BOD}_{5}$

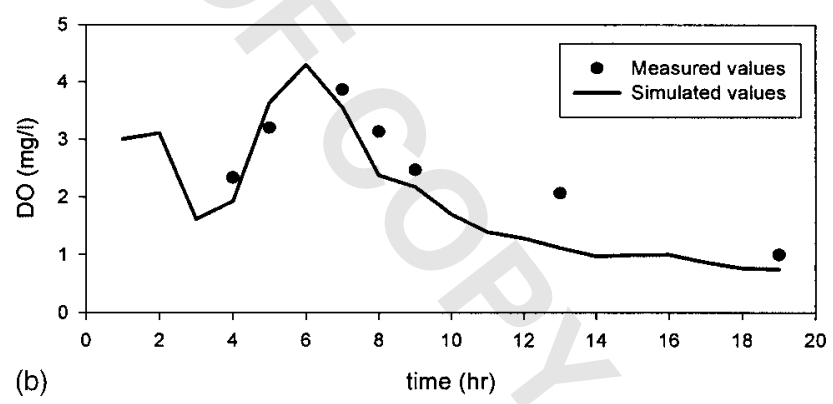

Model calibration in terms of DO

Fig. 10. Calibration of Love River Hydrodynamic and Water Quality and the measured values observed at R2 July 25, 2001

The formulations of the submodel used in the objective function are as follows:

$$
\begin{gathered}
\operatorname{Qcut}_{j}=C_{1 j}+b_{1 j} T_{j} \quad \text { if } R<30 ; \quad j=1,2,3,4 \\
=C_{2 j}+b_{2 j} T_{j} \quad \text { if } \quad R \geqslant 30 ; \quad j=1,2,3,4
\end{gathered}
$$

where $Q c u t_{j}=$ intercepted volume of CSOs at each gate $\left(M^{3}\right)$; $R=$ rainfall intensity $(\mathrm{mm} / \mathrm{h}) ; T_{1}=$ time period used for interception of CSOs at G1 gate ( $\mathrm{min}) ; T_{2}=$ time period used for interception of CSOs at $\mathrm{G} 2$ gate $(\mathrm{min}) ; T_{3}=$ time period used for interception of CSOs at G3 gate (min); $T_{4}=$ time period used for interception of CSOs at G4 gate (min); and

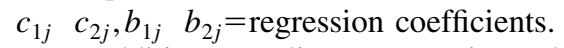

In addition, two linear regression submodels applied to illustrate the casual effect between DO levels and influential factors selected are formulated as follows:

$$
\begin{aligned}
& \mathrm{DO}_{\mathrm{ave}}=a_{0}+a_{1} T_{1}+a_{2} T_{2}+a_{3} T_{3}+a_{4} T_{4}+a_{5} Q w+a_{6} R \\
& \mathrm{DO}_{i}=s_{0 i}+s_{1 i} T_{1}+s_{2 i} T_{2}+s_{3 i} T_{3}+s_{4 i} T_{4}+s_{5 i} Q w+s_{6 i} R
\end{aligned}
$$

where $\mathrm{DO}_{\text {ave }}=$ average DO concentration in the entire region $(\mathrm{mg} /$ $\mathrm{L}) ; \mathrm{DO}_{i}=$ minimum DO concentration in each river reach $(\mathrm{mg} / \mathrm{L})$; $Q w=$ initial $\mathrm{BOD}_{5}$ concentration in the river before receiving CSOs (mg/L): $a_{0} \quad a_{6}=$ regression coefficients of the average DO concentration in the entire region $(\mathrm{mg} / \mathrm{L})$; and $s_{0 i} s_{6 i}=$ regression coefficients of the minimum DO concentration in river reach $i(i$ $=1,2, \ldots, 42)(\mathrm{mg} / \mathrm{L})$.

The optimization model can then be formulated as follows.

Objective Function. The objective function is designed to minimize the intercepted overflows of which some of them can be handled at a constant level by the trunk sewer destined to the coastal wastewater treatment plant, while the others must be stored in a temporary facility. That is

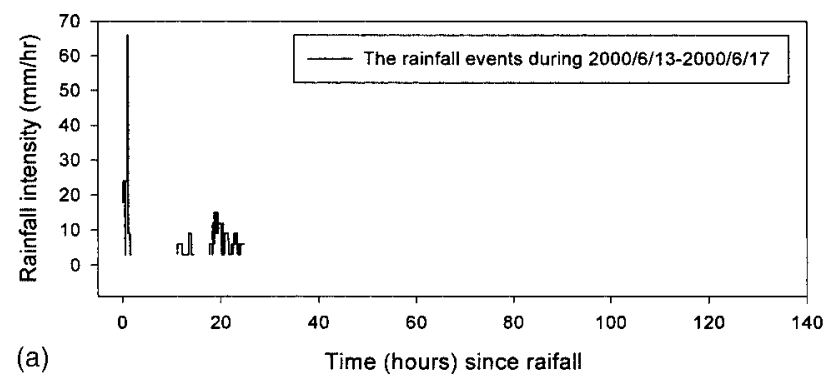

The rainfall events applied for LRHWQ verification

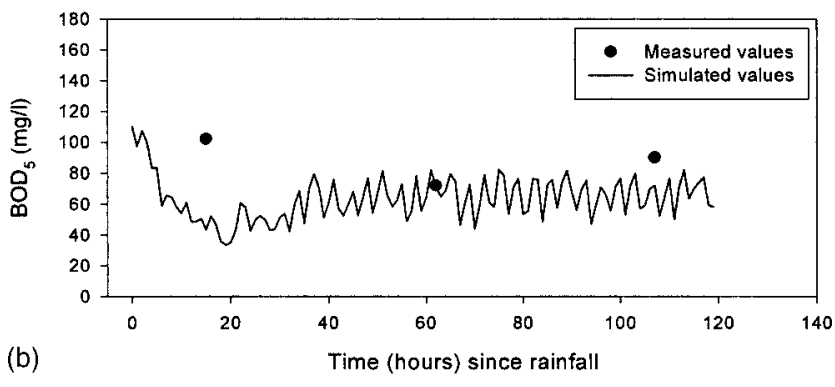

Model verification in terms of $\mathrm{BOD}_{5}$

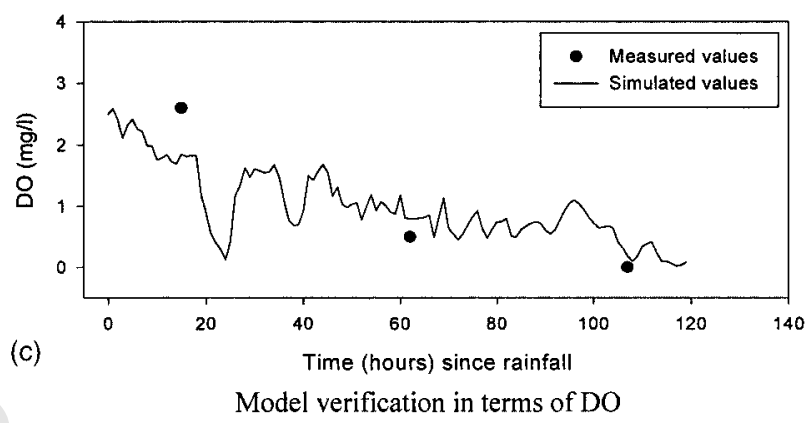

Fig. 11. Verification of Love River Hydrodynamic and Water Quality and the measured values observed at R4 June 13-17, 2000

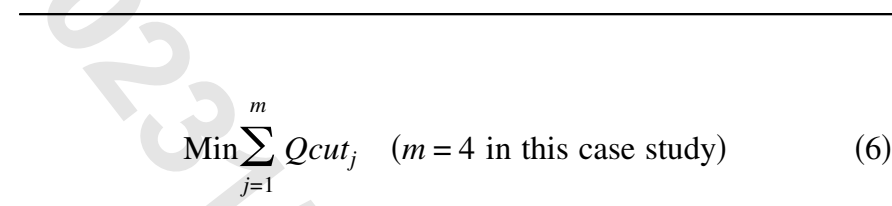

where $Q_{c u t}$ represents the runoff effluents being intercepted at each gate $\left(M^{3}\right)$.

\section{Constraints}

1. The ecological impact constraint: This constraint ensures that the DO concentration in the entire study region on average should be no less than a minimum level in an individual storm event.

$$
\mathrm{DO}_{\text {ave }} \geqslant H
$$

where $\mathrm{DO}_{\mathrm{ave}}=$ average $\mathrm{DO}$ concentration in the whole region (mg/L); and $H=$ standard chosen for the fish community (3 $\mathrm{mg} / \mathrm{L}$ in this study).

2. The critical limit constraint: The constraint assures that the DO level in any reach should be no less than the critical limit ecologically. This consideration would protect the fry in the storm events, because their adaptive capability to the changing environment is relatively low. It may also avoid producing the situation of "fish traps" in the river system (i.e., discharge CSOs into dead-end canals so that some of the young fish could have no chance to escape). 
Table 5. Derivation of Regression Submodel to Account for $Q_{c u t}$

\begin{tabular}{|c|c|c|c|c|c|c|c|c|}
\hline Qcut $_{j}$ & $\begin{array}{c}\text { Rainfall } \\
\text { pattern }\end{array}$ & $\begin{array}{c}\text { Time used } \\
\text { for interception } \\
\quad(\min )\end{array}$ & $b_{1 j}$ & $b_{2 j}$ & $c_{1 j}$ & $c_{2 j}$ & $F$ & $R^{2}$ \\
\hline \multirow[t]{5}{*}{$j=1$} & Fine rain & $<30$ & 510 & & $-4,202$ & & 8 & 0.88 \\
\hline & & $>=30$ & & 3,351 & & $-90,237$ & 1,868 & 0.99 \\
\hline & Heavy rain & $<30$ & 627 & & $-6,428$ & & 6 & 0.86 \\
\hline & & $>=30$ & & & & $-31,139$ & & \\
\hline & & & & 10,323 & & 8 & 131 & 0.98 \\
\hline \multirow[t]{4}{*}{$j=2$} & Fine rain & $<30$ & 10 & & -37 & & 60 & 0.98 \\
\hline & 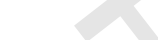 & $>=30$ & & 31 & & -716 & 148 & 0.98 \\
\hline & Heavy rain & $<30$ & 11 & & -53 & & 32 & 0.96 \\
\hline & & $>=30$ & & 110 & & $-3,318$ & 38 & 0.95 \\
\hline \multirow[t]{4}{*}{$j=3$} & Fine rain & $<30$ & 105 & & -813 & & 16 & 0.94 \\
\hline & & $>=30$ & & 404 & & $-9,961$ & 469 & 0.99 \\
\hline & Heavy rain & $<30$ & 136 & & $-1,234$ & & 9 & 0.9 \\
\hline & & $>=30$ & & 1,422 & & $-42,409$ & 70 & 0.97 \\
\hline \multirow[t]{4}{*}{$j=4$} & Fine rain & $<30$ & 42 & & -432 & & 6 & 0.84 \\
\hline & & $>=30$ & & 198 & & $-4,826$ & 183 & 0.98 \\
\hline & Heavy rain & $<30$ & 53 & & -583 & & 5 & 0.82 \\
\hline & & $>=30$ & & 607 & & $-17,269$ & 770 & 0.99 \\
\hline
\end{tabular}

$$
\mathrm{DO}_{i} \geqslant L
$$

where $\mathrm{DO}_{i}=$ minimum $\mathrm{DO}$ concentration in each river reach (mg/L); and $L=$ critical limit of DO to fry in the river system $(0.5 \mathrm{mg} / \mathrm{L}$ in this study).

3. The antianaerobic constraint: This constraint ensures that the river water will never become anaerobic to allow the release of ammonia in a reducing environment in some sensitive part of water body. This constraint is sometimes optional.

$$
\mathrm{DO}_{i} \geqslant 0
$$

\section{Results and Discussions}

\section{Fish Richness and Rainfall Impact}

The rainfall events measured in the Kaohsiung area can be generally classified into three different types, including fine rain (i.e., total accumulated rainfall is smaller than $30 \mathrm{~mm}$ and the maximum rainfall intensity is lower than $10 \mathrm{~mm} / \mathrm{h}$ ), heavy rain (i.e., total accumulated rainfall is between 30 and $100 \mathrm{~mm}$, and the maximum rainfall intensity is higher than $10 \mathrm{~mm} / \mathrm{h}$ ), and torrential rain (i.e., total accumulated rainfall is higher than $100 \mathrm{~mm}$ ). According to the meteorological observations during the time period between 1993 and 1997, there were 86 rainfall events recorded. The collected data include the records of 67 fine rain events (78\%), 16 heavy rain events (18\%), and 3 torrential ran events (3\%). Fig. 4 shows that there exists an internal consistency between lower biodiversity in the Love River and higher rainfall intensity in the Kaohsiung area, based on the investigation from August 1997 to August 1998. Obviously, when the richness of fish species reaches a maximum in December 1997, there were almost no rainfall events during that winter season. But still, fewer than 20 fish species could be found in the Love River; while more than 60 fish species were captured in the adjacent coastal region in this sampling campaign. Fig. 5 summarizes the frequency distributions associated with harmful and lethal conditions with respect to the fish community during the last decade (i.e., 1991-2000). On average, 65 and 75\% of rainfall events occur in the wet season that could result in either harmful or lethal conditions in the river system. As a result, there was an urgent need to develop an integrated modeling system for realtime assessment in the storm events. It will rely on two simulation-modeling practices that have been well calibrated and verified in advance.

\section{Calibration and Verification of the Storm Water Management Model}

Calibration and verification of $S W M M$ were performed by first measuring or assuming parameter values, then running the model and adjusting them manually, until the observed and simulated values were in acceptable agreement. Calibration was accomplished based on the rainfall event observed on July 25, 2001. Fig. 6 presents the calibration efforts with respect to four different gate locations. A fairly good match confirms the fact that run-off patterns at different gate locations are predictable in the storm events. Fig. 7 also produces significant predication accuracy with respect to $\mathrm{BOD}_{5}$ waste load in the run-off anticipated and achieved at four different gate locations. To further ensure the application potential, verification was performed on the rainfall event observed on July 11, 2001. Fig. 8 presents the verification efforts with respect to four different gate locations. There exists a relatively good match between the simulated and the predicted values in each case. Fig. 9 finally confirms the credibility for these predictions of $\mathrm{BOD}_{5}$ waste load accounting for CSO impacts. Based on the data of base flow being measured at G1, G2, G3, and G4 in Table 1, the waste load in the discharged effluents at these gates during the storm event on July 11, 2001 can be calculated by the combination of both impacts from the base flow 
Table 6. Derivation of Regression Submodel to Account for $\mathrm{DO}_{i}$ at Ebb Tide

\begin{tabular}{|c|c|c|c|c|c|c|c|c|c|}
\hline $\mathrm{DO}_{i}$ & $s_{0 i}$ & $s_{1 i}$ & $s_{2 i}$ & $s_{3 i}$ & $s_{4 i}$ & $s_{5 i}$ & $s_{6 i}$ & $F$ & $R^{2}$ \\
\hline$i=1$ & 3.5446 & & & & -0.0187 & -0.0164 & -0.0215 & 5 & 0.98 \\
\hline$i=2$ & 3.6871 & & & & -0.0147 & -0.0215 & -0.0296 & 9 & 0.98 \\
\hline$i=3$ & 3.5558 & & & & -0.0113 & -0.0202 & -0.0298 & 11 & 0.98 \\
\hline$i=4$ & 3.5892 & & & & & -0.0196 & -0.0317 & 19 & 0.99 \\
\hline$i=5$ & 3.8604 & & & & & -0.0228 & -0.0345 & 33 & 0.99 \\
\hline$i=6$ & 3.9222 & & & & & -0.0249 & -0.0364 & 101 & 0.99 \\
\hline$i=7$ & 3.8192 & 0.0041 & & -0.0009 & 0.0044 & -0.0261 & -0.0370 & 142 & 0.99 \\
\hline$i=8$ & 3.7976 & 0.0048 & -0.0033 & & 0.0062 & -0.0275 & -0.0377 & 210 & 0.99 \\
\hline$i=9$ & 4.1392 & 0.0052 & -0.0050 & & 0.0041 & -0.0294 & -0.0382 & 102 & 0.99 \\
\hline$i=10$ & 4.3262 & 0.0044 & -0.0085 & & 0.0035 & -0.0293 & -0.0376 & 335 & 0.99 \\
\hline$i=11$ & 4.0716 & 0.0039 & -0.0119 & 0.0066 & 0.0088 & -0.0299 & -0.0379 & 198 & 0.99 \\
\hline$i=12$ & 4.0150 & 0.0039 & -0.0119 & 0.0069 & 0.0107 & -0.0308 & -0.0384 & 213 & 0.99 \\
\hline$i=13$ & 3.9527 & 0.0040 & -0.0115 & 0.0066 & 0.0115 & -0.0302 & -0.0383 & 197 & 0.99 \\
\hline$i=14$ & 3.7576 & 0.0053 & -0.0108 & 0.0078 & 0.0140 & -0.0313 & -0.0388 & 187 & 0.99 \\
\hline$i=15$ & 3.7050 & 0.0052 & -0.0115 & 0.0086 & 0.0157 & -0.0325 & -0.0390 & 254 & 0.99 \\
\hline$i=16$ & 3.8282 & 0.0049 & -0.0128 & 0.0079 & 0.0155 & -0.0325 & -0.0391 & 240 & 0.99 \\
\hline$i=17$ & 3.9013 & 0.0051 & -0.0136 & 0.0077 & 0.0146 & -0.0321 & -0.0390 & 245 & 0.99 \\
\hline$i=18$ & 3.8182 & 0.0063 & -0.0140 & 0.0090 & 0.0156 & -0.0331 & -0.0393 & 267 & 0.99 \\
\hline$i=19$ & 3.7856 & 0.0072 & -0.0148 & 0.0101 & 0.0157 & -0.0337 & -0.0392 & 295 & 0.99 \\
\hline$i=20$ & 3.7928 & 0.0076 & -0.0159 & 0.0106 & 0.0153 & -0.0333 & -0.0387 & 296 & 0.99 \\
\hline$i=21$ & 3.8485 & 0.0074 & -0.0162 & 0.0099 & 0.0144 & -0.0321 & -0.0384 & 283 & 0.99 \\
\hline$i=22$ & 3.8708 & 0.0074 & -0.0166 & 0.0093 & 0.0144 & -0.0311 & -0.0383 & 235 & 0.99 \\
\hline$i=23$ & 3.8287 & 0.0075 & -0.0166 & 0.0093 & 0.0148 & -0.0302 & -0.0384 & 216 & 0.99 \\
\hline$i=24$ & 3.7924 & 0.0076 & -0.0169 & 0.0090 & 0.0165 & -0.0298 & -0.0389 & 168 & 0.99 \\
\hline$i=25$ & 3.8980 & 0.0061 & -0.0183 & 0.0076 & 0.0154 & -0.0267 & -0.0380 & 157 & 0.99 \\
\hline$i=26$ & 4.0689 & 0.0037 & -0.0196 & 0.0049 & 0.0128 & -0.0225 & -0.0359 & 214 & 0.99 \\
\hline$i=27$ & 4.3070 & & -0.0191 & & 0.0077 & -0.0182 & -0.0328 & 987 & 0.99 \\
\hline$i=28$ & 4.2407 & & -0.0166 & & 0.0069 & -0.0207 & -0.0335 & 88 & 0.99 \\
\hline$i=29$ & 4.0492 & 0.0036 & -0.0179 & 0.0046 & 0.0148 & -0.0237 & -0.0359 & 114 & 0.99 \\
\hline$i=30$ & 4.1391 & & -0.0184 & 0.0043 & 0.0141 & -0.0231 & -0.0351 & 105 & 0.99 \\
\hline$i=31$ & 4.1249 & 0.0030 & -0.0183 & 0.0053 & 0.0132 & -0.0227 & -0.0346 & 130 & 0.99 \\
\hline$i=32$ & 4.0642 & 0.0041 & -0.0180 & 0.0066 & 0.0128 & -0.0235 & -0.0339 & 130 & 0.99 \\
\hline$i=33$ & 3.9516 & 0.0053 & -0.0174 & 0.0079 & 0.0137 & -0.0242 & -0.0337 & 116 & 0.99 \\
\hline$i=34$ & 3.9256 & 0.0071 & -0.0171 & 0.0083 & 0.0124 & -0.0253 & -0.0320 & 92 & 0.99 \\
\hline$i=35$ & 3.9162 & 0.0082 & -0.0169 & 0.0090 & 0.0107 & -0.0253 & -0.0306 & 88 & 0.99 \\
\hline$i=36$ & 3.8729 & 0.0099 & -0.0170 & 0.0101 & 0.0086 & -0.0251 & -0.0286 & 56 & 0.99 \\
\hline$i=37$ & 3.8500 & 0.0105 & -0.0167 & 0.0095 & 0.0080 & -0.0239 & -0.0267 & 38 & 0.99 \\
\hline$i=38$ & 3.7813 & 0.0103 & -0.0137 & 0.0086 & 0.0066 & -0.0230 & -0.0248 & 31 & 0.99 \\
\hline$i=39$ & 3.5297 & 0.0088 & -0.0083 & 0.0073 & 0.0072 & -0.0209 & -0.0225 & 27 & 0.99 \\
\hline$i=40$ & 3.3552 & 0.0057 & -0.0026 & 0.0050 & 0.0067 & -0.0178 & -0.0195 & 49 & 0.99 \\
\hline$i=41$ & 3.4153 & 0.0066 & -0.0036 & 0.0074 & & -0.0136 & -0.0178 & 51 & 0.99 \\
\hline$i=42$ & 2.6307 & 0.0053 & -0.0039 & 0.0066 & & -0.0023 & -0.0112 & 13 & 0.98 \\
\hline
\end{tabular}

in dry conditions and the runoff in the storm event, as shown in Figs. 6-9.

\section{Calibration and Verification of the Love River Hydrodynamic and Water Quality}

The surface water quality modeling system $(L R H W Q)$, which was used in conjunction with $S W M M$ in this study, was applied to postprocess the $S W M M$ output and preprocess the data required for optimization analysis. The first phase was the generation of a two-dimensional mesh for $L R H W Q$ analysis. Flow velocities and water elevations in the estuarine region were calculated by $L R H W Q$ and saved to a temporary file. Then these data were used to perform the hydrodynamic, contaminant migration, and sedi- ment transport simulations for the tidal reaches. The practice of model calibration was carried out for both parameters of $\mathrm{BOD}_{5}$ and DO based on the field data observed on July 25, 2001. Fig. 10 depicts several comparisons between the model output and field data. Reasonable agreement is reached and predication accuracy can be confirmed. The calibrated model was then applied to ensure the higher application potential based on the data collected at the $\mathrm{Wu}-\mathrm{Fu}$ Bridge between June 13 and 17, 2000. A stratified random sampling was undertaken at different strata in the estuary region, which are used to generate the average values of the data in the upper and lower layers. Fig. 11 implies that a considerable agreement between the measured and the simulated values can be confirmed at least at the $\mathrm{Wu}-\mathrm{Fu}$ Bridge. 
Table 7. Derivation of Regression Submodel to Account for $\mathrm{DO}_{i}$ at Rise Tide

\begin{tabular}{|c|c|c|c|c|c|c|c|c|c|}
\hline $\mathrm{DO}_{i}$ & $s_{0 i}$ & $s_{1 i}$ & $s_{2 i}$ & $s_{3 i}$ & $s_{4 i}$ & $s_{5 i}$ & $s_{6 i}$ & $F$ & $R^{2}$ \\
\hline$i=1$ & 3.2788 & & & & -0.0169 & -0.0174 & -0.0219 & 12 & 0.98 \\
\hline$i=2$ & 3.5469 & & & & & -0.0248 & -0.0309 & 10 & 0.98 \\
\hline$i=3$ & 3.4252 & & & & & -0.0226 & -0.0312 & 16 & 0.98 \\
\hline$i=4$ & 3.8568 & & & & & -0.0245 & -0.0339 & 33 & 0.99 \\
\hline$i=5$ & 4.0292 & & & & & -0.0257 & -0.0353 & 123 & 0.99 \\
\hline$i=6$ & 3.9359 & 0.0014 & -0.0034 & & 0.0052 & -0.0277 & -0.0370 & 1238 & 0.99 \\
\hline$i=7$ & 3.9721 & 0.0017 & -0.0046 & 0.0013 & 0.0073 & -0.0297 & -0.0384 & 54,918 & 0.99 \\
\hline$i=8$ & 4.1955 & & -0.0072 & 0.0011 & 0.0077 & -0.0303 & -0.0388 & 7,445 & 0.99 \\
\hline$i=9$ & 4.3464 & & -0.0079 & & 0.0064 & -0.0308 & -0.0387 & 799 & 0.99 \\
\hline$i=10$ & 4.1586 & 0.0026 & -0.0096 & 0.0038 & 0.0086 & -0.0318 & -0.0389 & 6,799 & 0.99 \\
\hline$i=11$ & 3.7674 & 0.0038 & -0.0117 & 0.0121 & 0.0149 & -0.0346 & -0.0400 & 347 & 0.99 \\
\hline$i=12$ & 3.7666 & 0.0033 & -0.0120 & 0.0122 & 0.0159 & -0.0350 & -0.0402 & 601 & 0.99 \\
\hline$i=13$ & 3.8022 & 0.0028 & -0.0125 & 0.0118 & 0.0159 & -0.0344 & -0.0400 & 921 & 0.99 \\
\hline$i=14$ & 3.7065 & 0.0032 & -0.0128 & 0.0130 & 0.0183 & -0.0362 & -0.0403 & 4,284 & 0.99 \\
\hline$i=15$ & 3.7499 & 0.0024 & -0.0131 & 0.0132 & 0.0182 & -0.0368 & -0.0398 & 6,238 & 0.99 \\
\hline$i=16$ & 3.8137 & 0.0020 & -0.0144 & 0.0131 & 0.0178 & -0.0365 & -0.0394 & 2,293 & 0.99 \\
\hline$i=17$ & 3.8413 & 0.0019 & -0.0154 & 0.0140 & 0.0169 & -0.0360 & -0.0390 & 535 & 0.99 \\
\hline$i=18$ & 3.8910 & & -0.0172 & 0.0146 & 0.0164 & -0.0360 & -0.0384 & 257 & 0.99 \\
\hline$i=19$ & 3.9162 & & -0.0174 & 0.0147 & 0.0157 & -0.0355 & -0.0383 & 161 & 0.99 \\
\hline$i=20$ & 3.9431 & & -0.0181 & 0.0141 & 0.0164 & -0.0348 & -0.0383 & 180 & 0.99 \\
\hline$i=21$ & 3.9471 & & -0.0182 & 0.0138 & 0.0164 & -0.0340 & -0.0383 & 165 & 0.99 \\
\hline$i=22$ & 3.9802 & & -0.0192 & 0.0127 & 0.0166 & -0.0331 & -0.0382 & 281 & 0.99 \\
\hline$i=23$ & 3.9994 & & -0.0196 & 0.0122 & 0.0165 & -0.0322 & -0.0381 & 339 & 0.99 \\
\hline$i=24$ & 4.0206 & 0.0022 & -0.0203 & 0.0106 & 0.0174 & -0.0312 & -0.0383 & 1,512 & 0.99 \\
\hline$i=25$ & 4.0257 & 0.0021 & -0.0204 & 0.0102 & 0.0173 & -0.0300 & -0.0384 & 7,071 & 0.99 \\
\hline$i=26$ & 4.0521 & 0.0034 & -0.0223 & 0.0085 & 0.0183 & -0.0295 & -0.0381 & 412 & 0.99 \\
\hline$i=27$ & 3.7990 & 0.0054 & -0.0194 & 0.0056 & 0.0147 & -0.0257 & -0.0349 & 6,258 & 0.99 \\
\hline$i=28$ & 3.7947 & 0.0053 & -0.0177 & 0.0027 & 0.0132 & -0.0246 & -0.0333 & 571 & 0.99 \\
\hline$i=29$ & 3.7621 & 0.0039 & -0.0191 & 0.0048 & 0.0170 & -0.0236 & -0.0337 & 82 & 0.99 \\
\hline$i=30$ & 3.7691 & 0.0041 & -0.0185 & 0.0054 & 0.0175 & -0.0247 & -0.0339 & 84 & 0.99 \\
\hline$i=31$ & 3.9892 & 0.0027 & -0.0182 & 0.0057 & 0.0155 & -0.0251 & -0.0343 & 371 & 0.99 \\
\hline$i=32$ & 4.0634 & 0.0024 & -0.0177 & 0.0071 & 0.0140 & -0.0258 & -0.0340 & 6,852 & 0.99 \\
\hline$i=33$ & 3.9675 & 0.0028 & -0.0170 & 0.0076 & 0.0125 & -0.0244 & -0.0320 & 2,378 & 0.99 \\
\hline$i=34$ & 3.9275 & 0.0052 & -0.0179 & 0.0084 & 0.0110 & -0.0250 & -0.0302 & 7,034 & 0.99 \\
\hline$i=35$ & 3.8059 & 0.0080 & -0.0181 & 0.0101 & 0.0087 & -0.0250 & -0.0273 & 448 & 0.99 \\
\hline$i=36$ & 3.8761 & 0.0095 & -0.0185 & 0.0100 & 0.0061 & -0.0258 & -0.0252 & 111 & 0.99 \\
\hline$i=37$ & 3.7467 & 0.0087 & -0.0155 & -0.0071 & 0.0087 & -0.0245 & -0.0237 & 31 & 0.99 \\
\hline$i=38$ & 3.8654 & 0.0102 & -0.0159 & 0.0065 & 0.0060 & -0.0247 & -0.0226 & 17 & 0.99 \\
\hline$i=39$ & 3.7932 & 0.0102 & -0.0146 & & 0.0078 & -0.0230 & -0.0222 & 12 & 0.98 \\
\hline$i=40$ & 3.8134 & 0.0101 & -0.0139 & & 0.0082 & -0.0216 & -0.0210 & 6 & 0.97 \\
\hline$i=41$ & 3.5305 & 0.0100 & -0.0089 & & 0.0050 & -0.0186 & -0.0175 & 5 & 0.96 \\
\hline$i=42$ & 3.0955 & 0.0063 & -0.0060 & 0.0055 & 0.0021 & -0.0118 & -0.0149 & 52 & 0.99 \\
\hline
\end{tabular}

\section{Minimizing the Ecological Risk during Combined-Sewer Overflow}

An important part of CSO control system planning is the determination of an optimal control scheme for each gate operation that could serve as a break-even point between the required storage volumes versus ecological impact. The integration of two simulation models (i.e., $S W M M$ and $L R H W Q$ ), being calibrated and verified, enables the creation of a new groundbreaking optimization application of mathematical programming for ecological risk assessment. To meet a wide range of specific development and implementation needs in preferred model interactions, the integrated model may be regarded as an effective simulator to aid in deriving those regression submodels, and also to perform op- timization analysis. Tables 5-8 present the regression coefficients associated with these three submodels. Most $F$ values are statistically significant under the inference test at the $5 \%$ level of significance.

This analysis offers three distinctive sets of constraints in optimization scenarios for embedding two safety levels (i.e., safety level I and II) from an ecological sense into end-use applications, allowing for greater flexibility, ease-of-maintenance of the mathematical algorithm, and significantly reduced time in future assessments. Table 9 depicts several planning scenarios associated with different technical settings. For sizing a storage pond in the sewer system when the duration of the rainfall event is below $1 \mathrm{~h}$, the required interception of CSOs can be addressed in terms of 
Table 8. Deviation of Regression Submodel to Account for $\mathrm{DO}_{\text {avg }}$ at Ebb Tide and at Rise Tide

\begin{tabular}{cccccccccc}
\hline $\mathrm{DO}_{\mathrm{ave}}$ & $a_{0}$ & $a_{1}$ & $a_{2}$ & $a_{3}$ & $a_{4}$ & $a_{5}$ & $a_{6}$ & $F$ \\
\hline & 4.2590 & 0.0050 & -0.0063 & 0.0042 & 0.0014 & -0.0223 & -0.0252 & 788 & 0.99 \\
& 4.2719 & 0.0038 & -0.0062 & 0.0050 & 0.0015 & -0.0223 & -0.0250 & 5335 & 0.99 \\
\hline
\end{tabular}

Note: $\mathrm{DO}=$ dissolved oxygen.

Table 9. Optimization Scenarios Designed for Minimizing Ecologic Risk

\begin{tabular}{|c|c|c|c|c|}
\hline $\begin{array}{c}\text { Goal for } \\
\text { minimizing } \\
\text { ecological risk }\end{array}$ & $\begin{array}{c}\text { Constraint } \\
\text { set I }\end{array}$ & $\begin{array}{c}\text { Constraint } \\
\text { set II }\end{array}$ & $\begin{array}{l}\text { Constraint } \\
\text { set III }\end{array}$ & $\begin{array}{c}\text { Solution } \\
\text { of the optimal } \\
\text { model }\end{array}$ \\
\hline Safety level I & $\$$ & $\%$ & $\%$ & Feasible as rainfall intensity is less than $50 \mathrm{~mm} / \mathrm{h}$ \\
\hline Safety level II & $\$$ & $\&$ & $\%$ & Feasible as rainfall intensity is less than $100 \mathrm{~mm} / \mathrm{h}$ \\
\hline
\end{tabular}
satisfy this constraint; and $\&=$ compliance with this constraint only in partial river reaches (segment 11-42).

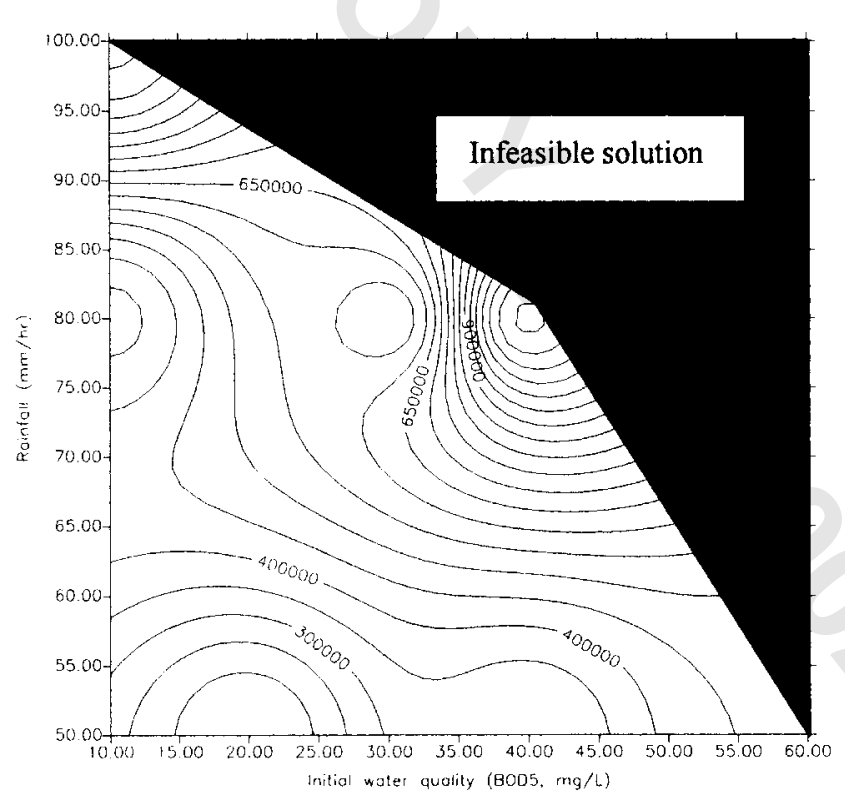

(a)

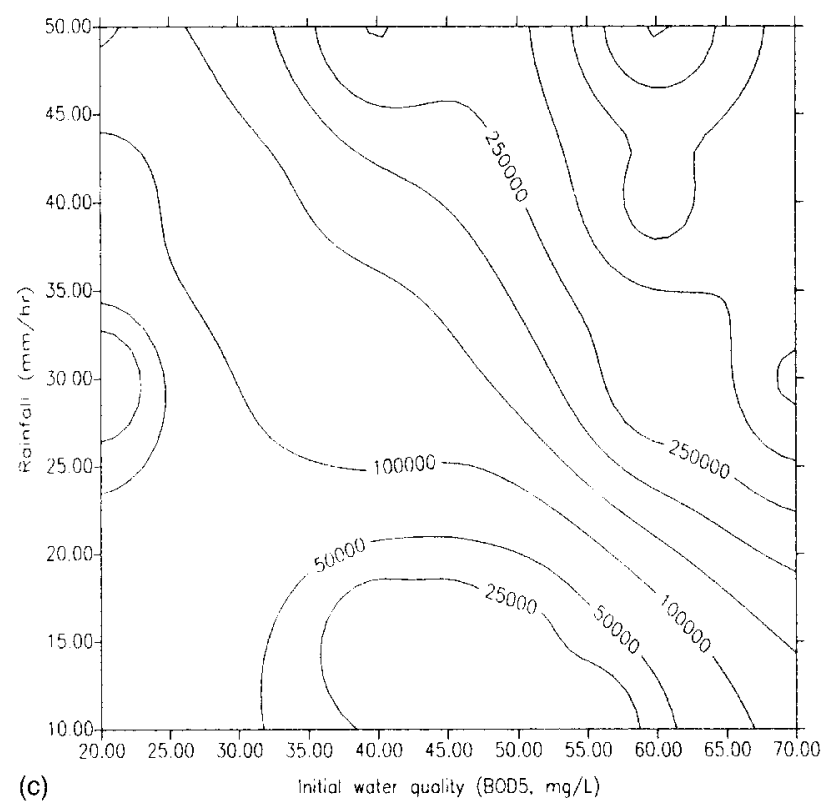

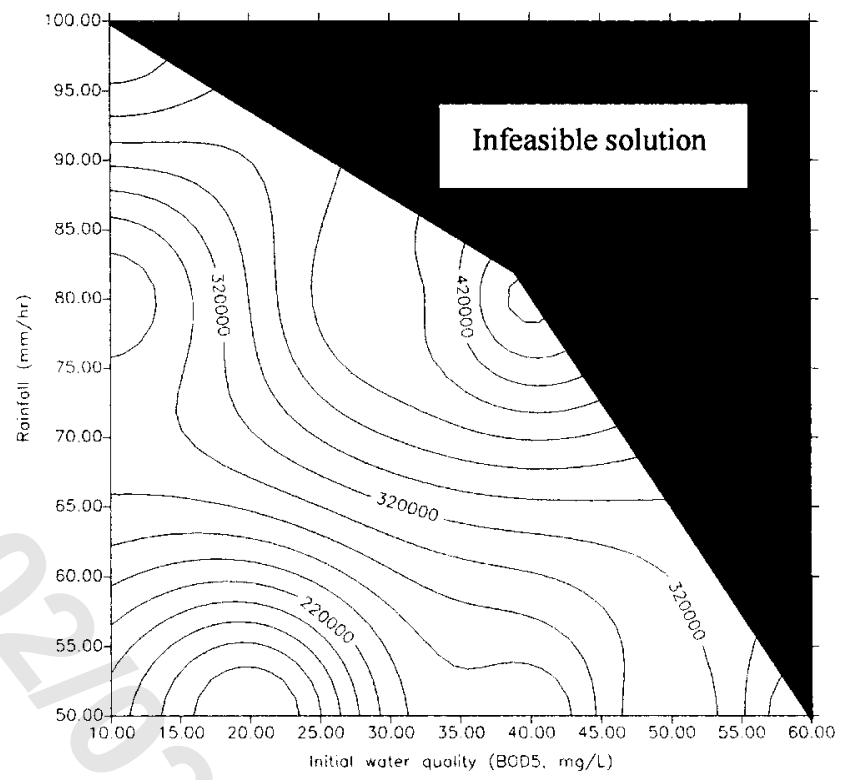

(b)

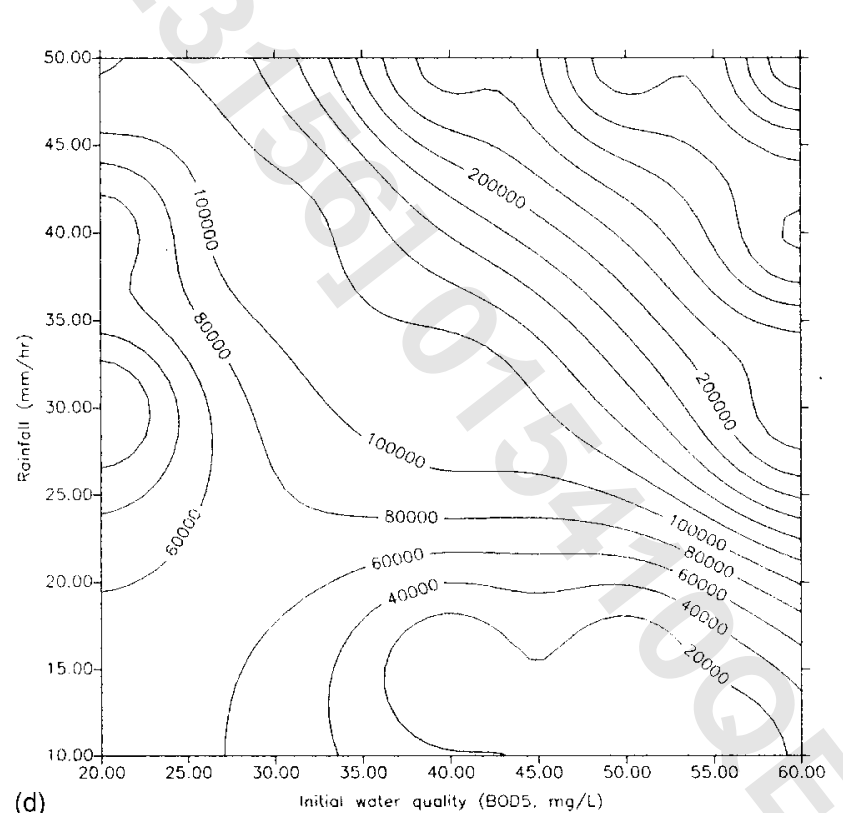

Fig. 12. Optimal size of interception of combined-sewer overflows in terms of initial water quality and rainfall intensity: (a) at ebb tide and Safety I condition; (b) at rise tide and Safety I condition; (c) at ebb tide and safety II condition; and (d) at rise tide and Safety II condition 


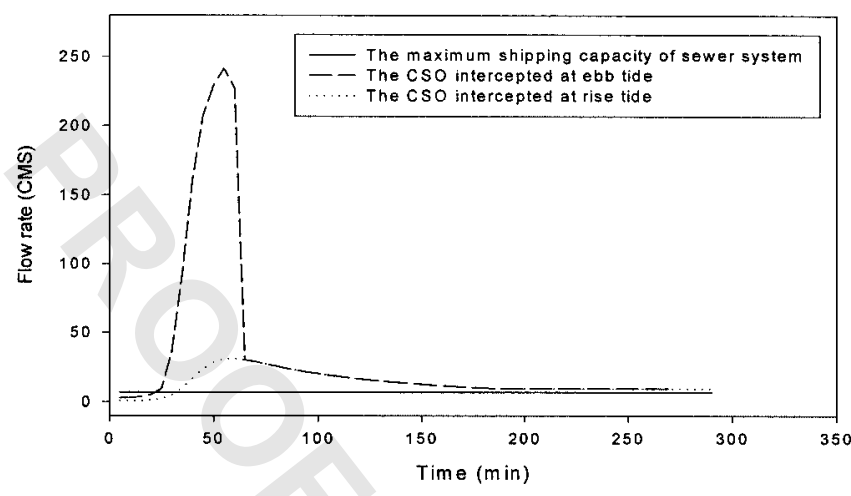

Fig. 13. Comparative advantage with respect to the minimum dissolved oxygen level achieved over all river reaches before and after implementing optimal control scheme based on the condition of Safety level II

the initial water quality in the river and the rainfall intensity in Fig. 12. Optimal solutions, however, cannot always be found in those cases at safety level I (associated with both rise tide and ebb tide conditions). In general, given that the maximum transport capacity of the trunk sewer is the main limiting factor, the required optimal size of storage increases as the rainfall intensity increases. In addition, the higher the initial $\mathrm{BOD}_{5}$ concentration in the river, the larger is the required storage pond volume. Since $78 \%$ of rainfall events in the Kaohsiung area belong to the category of heavy rainfall events, the contour lines shown in Fig. 12 may provide meaningful and applicable information for future engineering designs of storage ponds or expansions of the trunk sewers. Frequently in decision analysis, the system might have to be operated in concert under a condition of safety at level. II "What is the comparative advantage due to the implementation of an optimal control scheme?" can be a significant question. Fig. 13 demonstrates the minimum DO level achieved over all river reaches under investigation before and after implementing an optimal control scheme based on the condition of safety level II. It appears that the first ten segments designated in the river system are able to maintain the minimum DO level with respect to the antianaerobic requirement, while the rest of the segments designated in the river system satisfy the critical limit constraint. Although the overall average of DO level across 42 segments in the horizontal direction and six layers in the vertical direction can satisfy the ecological impact constraint, only a few minimum DO levels reach the value of $\mathrm{DO}_{\mathrm{avg}}$. The main advantage of implementing the optimal control scheme not only rests on the significant improvement of minimum DO level in all river reaches but also helps the fish community avoid the fish trap occurring at the gate G3 (i.e., $15 \mathrm{~km}$ from the Kaohsiung harbor), no matter whether it is in either ebb tide or rise tide condition.

For the purpose of demonstration, Table 10 shows a set of optimal control schemes at four main gates in the interceptor system associated with two types of tidal events. It is known that the maximum level of transport capacity via the current trunk sewer system is only $23,000 \mathrm{~m}^{3} / \mathrm{h}$. In the event of fine rain and heavy rain, in which rainfall intensity is smaller than $30 \mathrm{~mm} / \mathrm{h}$, analysis confirms that the wastewater treatment facility can handle all the stormwater impact. However, a significant portion of CSOs must be retained temporarily in a storage pond to reduce the direct ecological impact to the river in the event of torrential rain. In any circumstance, with regard to the goal of promotion of biodiversity in the river system, the interception of CSOs at gate $\mathrm{G} 3$ is the most influential action, since the pollution impacts from the associated drainage subbasin are significant. Proper control at gate G1 could also contribute to a substantial improvement in river water quality. The maximum level of CSOs to be intercepted for the cases at ebb tide and rise tide could be up to 1,014,702 and $414,118 \mathrm{~m}^{3}$ within $1 \mathrm{~h}$, respectively, when the storm event with a 25 -year return period (i.e., $100 \mathrm{~mm} / \mathrm{h}$ ) occurs. The results also imply that the relatively lower dilution capacity in ebb tide condition would require a higher level of interception in CSOs. Such optimal control strategies are proved applicable for most of the rainfall events and would be beneficial for improving the ecosystem biodiversity in the long run.

Based on the assessment above, a stormwater best manage-

Table 10. Optimal Control Schemes at All Main Gates Given That the Duration of Rainfall is $1 \mathrm{~h}$ at Ebb Tide and at Rise Tide

\begin{tabular}{|c|c|c|c|c|c|c|}
\hline \multirow[b]{2}{*}{$\begin{array}{l}\text { Rainfall } \\
\text { intensity } \\
(\mathrm{mm} / \mathrm{h})\end{array}$} & \multirow[b]{2}{*}{$\begin{array}{c}\text { Critical initial } \\
\text { water quality } \text { BOD }_{5} \\
(\mathrm{mg} / \mathrm{L})\end{array}$} & \multicolumn{4}{|c|}{ Time required for interception at gates before releasing CSO } & \multirow[b]{2}{*}{$\begin{array}{c}\text { Total CSO } \\
\left(\mathrm{m}^{3} \text { in }\right. \\
1 \mathrm{~h})\end{array}$} \\
\hline & & $\begin{array}{c}(\min ) \\
\mathrm{G} 1\end{array}$ & $\begin{array}{c}(\min ) \\
\text { G2 }\end{array}$ & $\begin{array}{c}(\min ) \\
\text { G3 }\end{array}$ & $\begin{array}{c}(\min ) \\
\text { G4 }\end{array}$ & \\
\hline 10 & 55 & - & - & - & 28 & 1,213 \\
\hline 15 & 50 & 27 & - & - & 30 & 15,157 \\
\hline 30 & 70 & - & - & 251 & - & 358,208 \\
\hline 40 & 60 & - & - & 258 & - & 368,027 \\
\hline 50 & 60 & - & - & 318 & - & 453,347 \\
\hline 80 & 40 & 75 & - & 292 & 31 & $1,215,581$ \\
\hline 100 & 10 & 58 & - & 272 & 33 & $1,014,702$ \\
\hline \multicolumn{7}{|l|}{ At rise tide } \\
\hline 10 & 55 & - & - & - & 18 & 779 \\
\hline 15 & 50 & - & - & - & 29 & 1,245 \\
\hline 30 & 60 & - & - & 163 & - & 232,098 \\
\hline 40 & 60 & - & - & 213 & - & 303,198 \\
\hline 50 & 60 & - & - & 263 & - & 374,298 \\
\hline 80 & 40 & - & - & 316 & 25 & 465,339 \\
\hline 100 & 10 & - & - & 288 & 8 & 414,118 \\
\hline
\end{tabular}

Note: $\mathrm{CSO}=$ combined-sewer overflow. 


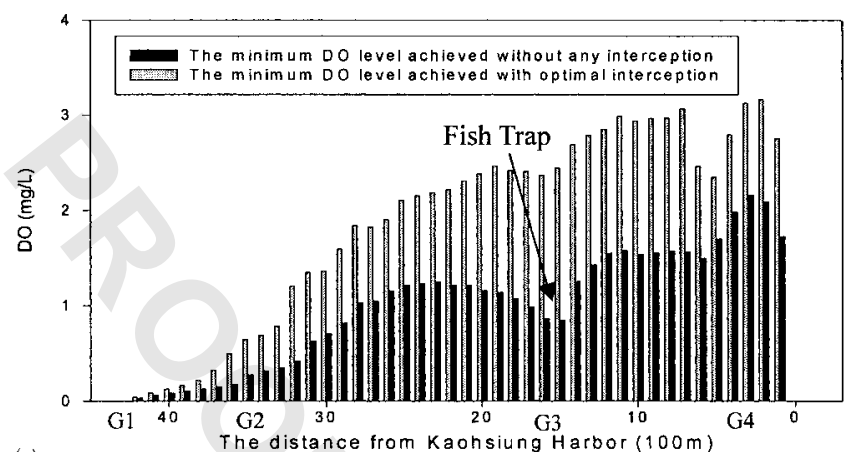

(a)

at ebb tide

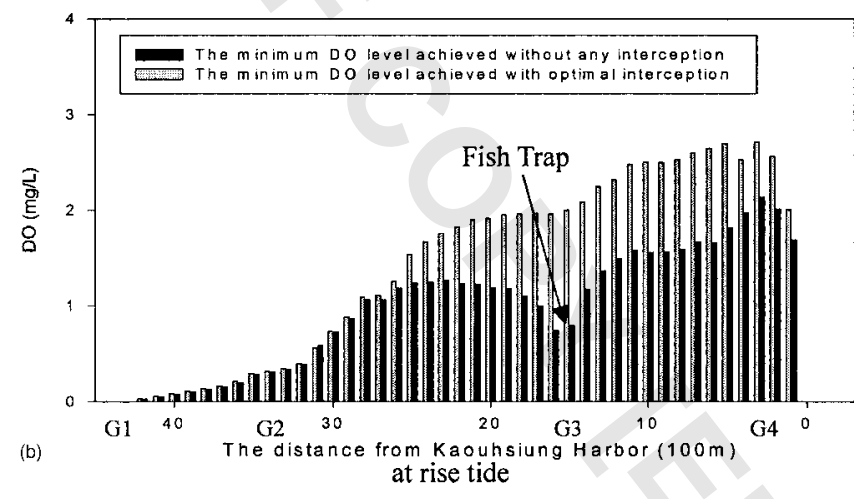

Fig. 14. Required interception of combined-sewer overflows during the rainfall event of $100 \mathrm{~mm} / \mathrm{h}$ compared with the maximum transport capacity of trunk sewer

ment practice (BMP), covering the essential measure or structural control that is used for a given set of conditions to manage the quantity and improve the quality of stormwater runoff in the most cost-effective manner, can be determined. BMPs can be either engineered and constructed systems ("structural BMPs") that improve the quality and/or control the quantity of runoff such as detention ponds and constructed wetlands, or they can be institutional, education, or pollution prevention practices designed to limit the generation of stormwater runoff or reduce the amounts of pollutants contained in the runoff ("nonstructural BMPs"). Finally, Fig. 14 compares the required interception of CSOs during a rainfall event of $10 \mathrm{~mm} / \mathrm{h}$ with the maximum transport capacity of current trunk sewer. Results indicate that additional storage capacity must be considered at all times in system planning, as it allows for maximum utilization of existing wastewater treatment facilities and results in the lowest pollutant level. Storage in reality can be applied upstream, midstream, or downstream at suitable points in the sewer system. Upstream storage can offer the dual benefits of drainage and flood relief/control. Types of storage facilities include unused capacity in the existing interceptor and sewer pipelines, conventional concrete tanks, lined earthen basins, and even tunnels and underground tanks.

\section{Conclusion}

The problem of lower biodiversity of fish species in the Love River estuarine system in the city of Kaohsiung, South Taiwan has long been affected by the impact of stormwater overflow. To address its gross impacts, this study not only exhibits a high degree of interdisciplinarity between different types of field surveys and modeling analyses in scientific perspectives, but also deter- mines the required engineering efforts to minimize the ecological risk to an urban river system. By placing biocomplexity or biodiversity studies in an environmental context, this environmental systems analysis calibrates, verifies, and integrates two types of simulation models as a whole to facilitate exploring, eliciting, and summarizing the interactions of natural systems and engineered systems. In conjunction with these efforts in an optimization analysis, analytical results successfully address an optimal control scheme for each gate operation during several typical storm events that clearly improves science-based predictive capabilities for decision-making. An additional storage facility with an optimal size can be engineered, which possesses the favorable attributes of being simple in structural design and operation, responding without difficulty to random storm behavior. It is anticipated that this research could serve as a pioneering work to describe the dynamics of coupled natural and human systems, providing a foundation for achieving the goals of urban-scale sustainability programs.

\section{Acknowledgment}

The writers acknowledge the helpful comments provided by anonymous referees in the reviewing process.

\section{References}

Alan, G. H. (1995). Water pollution and fish physiology, Lewis-CRC, Boca Raton, Fla.

Attrill, M. J. (1998). A rehabilitated estuarine ecosystem: The environment and ecology of the Thames estuary, Kluwer Academic, London.

Bikangaga, J. H., and Nassehi, V. (1995). "Application of computer modeling techniques to the determination of optimum effluent discharge policies in tidal water systems." Water Res., 29(10), 2367-2375

Cassar, A., and Verworn, H. R. (1999). "Modifications of rainfall runoff and decision finding models for on-line simulation in real time control." Water Sci. Technol., 39(1), 201-207.29.

Chen, J. C., Chang, Y. C., Chang, N. B., and Lee, M. T. (2002). "Mitigating the impact of combined sewer overflows to an urban river system via web-based shared-vision modeling analysis." Civ. Eng. Environ. Sys., in press.

Chen, M. H., and Hsiao, J. S.,(1996). "The reproductive biology of the Gizzard Shad: Nematalosa come in the Kaohsiung River and its harbor area, Southern Taiwan.” Zoolog. Studies 35(4), 261-271.

Chen, M. H., Wen, D. J., and Chen, C. Y. (1999). "Reproduction and estuarine utilization of the grey mullet, Liza macrolepis (Smith, 1846), in the area of Kaohsiung harbour, southern Taiwan." Fish. Sci. 65(1), $1-10$.

Curtis, L. D., and Tarang, K. (1997). "A steady-state model of the Willamette River: implications for flow control of dissolved oxygen and phytoplankton biomass." River water quality: Dynamics and restoration, Antonius Laenen and David A. Dunnette, eds., 163-185.

Entem, S., Lahound, A., Yde, L., and Bendsen, B. (1998). "Real time control of the sewer system of Boulogne Billancourt- a contribution to improving the water quality of the Seine.” Water Sci. Technol., 37(1), 319-326.

Environmental Protection Agency, Taiwan (EPA, Taiwain). (19931999).http://www.epa.gov.tw/Pl/Pl-6g.htm

Falconer, R. A., and Lin, B. (1997). "Three-dimensional modeling of water quality in the humber estuary." Water Res., 31, 1092-1102.

Fen, C. S. (2001). "Modeling wastewater discharge to the Ai Estuary, Kaohsiung, Taiwan." Water Qual. Ecosystem Model, in press.

Fruge, D. W. (1995). "U.S. Fish and wildlife service involvement in Louisiana coastal wetlands conservation and restoration task force 
activities." Coastal zone 95, B. L. Edge, ed., ASCE, New York, 3536.

Heath, A. G. (1995). Water pollution and fish physiology, Lewis-CRC, Boca Raton, Fla.

Huang, Y. H. (1996). "A study on species composition and seasonal abundance of ichthyoplankton in Kaohsiung River, its harbor area and the nearby coastal waters, southern Taiwan." master thesis, National SuYet-Sen University, Taiwan.

Huber, W. C., and Dickinson, R. E. (1988). Storm water management model user's manual, Version 4, EPA/600/3-88/001a (NTIS PB88236641/AS), Environmental Protection Agency, Athens. Ga.

Jones, E. (1964). Fish and river pollution, Butterworths, London, 5-26.

Lager, J. A. (1977). "Urban stormwater management and technologyUpdate and users' Guide." EPA-600/8-77-014, NTIS PB 275654, USEPA, ORD, Cincinnati.

Latimer, J. S., and Quinn, J. G. (1996). "Historical trends and current inputs of hydrophobic compounds is an urban estuary: the sedimentary record." Environ. Sci. Technol., 30, 623-633.

Leiser, C. P. (1974). "Computer management of a combined sewer system." EPA-670/2-74-022, NTIS PB 235717. US EPA ORD, Washington D.C.

Lorenz, J. M., and Koski, K. V. (1995). "Restoration of water quality and anadromous fish habitat in Duck Creek, and impaired urban stream in Juneau, Alaska." Coastal zone '95, B. L. Edge, ed., ASCE, New York, 94-95.

Moffa, P., ed. (1989). Control and treatment of combined-sewer overflows, Van Nostrand Reinhold, New York.

Ng, B., Turner, A., Tyler, A. O., Falconer, R. A., and Millward, G. E. (1996). "Modelling contaminat geochemistry in estuaries." Water Res., 30, 63-74.

Nyberg, U., Andersson, B., and Aspegren, H. (1996). "Real time control for minimizing effluent concentrations during storm water events." Water Sci. Technol., 34(3-4), 127-134.

Perguson, P. L., Iden, C. R., and Brownawell, B. J. (2001). "Distribution and fate of natural alkylphenol ethoxylate metabolites in a sewageimpacted urban estuary." Environ. Sci. Technol., 35, 2428-2435.

Petruck, A., Cassar, A., and Dettmar, J. (1998). "Advanced real time control of a combined sewer system." Water Sci. Technol., 37(1), 319-326.

Reda, A. L., and Beck, M. B. (1999). "Simulation model for real-time decision support in controlling the impacts of storm sewage discharges." Water Sci. Technol., 39, 225-233.

Roesner, L. A., Aldrich, J. A., and Dickinson, R. E. (1988). Storm water management model user's manual, version 4: Addendum I, EXTRAN, EPA/600-3-88/001b (NTIS PB88236658/AS), Environmental Protection Agency, Athens. Ga.

Seaman, G. A. (1995). "Assessment and control of cumulative impacts of coastal uses on fish habitat of the Kenai River, Alaska." Coastal zone '95, B. L. Edge, ed., ASCE, New York, 70-71.

United States Environmental Protection Agency (US EPA. (1993). Seminar Publication, National Conference on Urban Runoff Management: Enhancing Urban Watershed Management at the Local, County, and State Levels, The Westin Hotel, Chicago.

United States Environmental Protection Agency (US EPA. (1995). "Combined sewer overflows, guidance for nine minimum controls." EPA 832-B-95-003, Office of Wastewater Management, Washington, D.C.

Vaughan, W. J., and Russell, C. S. (1982). Freshwater recreational fish; The national benefits of water pollution control, Resource for the Future Press, Washington, D.C., 40-41.

Vazquez, J., Bellefleur, D., Gilbert, D., and Grandjean, B. (1997). "Real time control of a combined sewer network using graph theory." Water Sci. Technol., 36(5), 301-308.

Walesh, S., and Carr, R. (2000). "Street storage system for control of combined sewer surcharge: Retrofitting stormwater storage into combined sewer systems." EPA/600/R-00/065, US EPA, ORD, Cincinnati.

Weinreich, G., Schilling, W., Birkeley, A., and Moland, T. (1997). "Pollution based real time control stragies for combined sewer systems." Water Sci. Technol., 36(8-9), 331-336.

Whitehead, P. G., Williams, R. J., and Lewis, D. R. (1997). "Quality simulation along river systems (QUASAR): Model theory and development." Sci. Total Environ., 194/195, 447-456.

Wu, C. F. J., and Hamada, M. (2000). Experiments planning, analysis, and parameter design optimization, Wiley-Interscience, New York, 153-203. 